Breastfeeding characteristics of late-preterm infants in a kangaroo mother care unit.

by

Melissa Pike

A dissertation submitted in fulfilment of the requirements for the degree

MASpeech-Language Pathology

in the Department of Speech-Language Pathology and Audiology at the

UNIVERSITY OF PRETORIA

FACULTY OF HUMANITIES

SUPERVISOR: PROFESSOR ALTA KRITZINGER CO-SUPERVISOR: MS ESEDRA KRÜGER

July 2017 


\section{UNIVERSITY OF PRETORIA}

FACULTY OF HUMANITIES

DEPARTMENT OF SPEECH-LANGUAGE PATHOLOGY AND AUDIOLOGY

\begin{tabular}{|l|l|}
\hline $\begin{array}{l}\text { Surname: } \\
\text { Initials: }\end{array}$ & $\begin{array}{l}\text { Pike } \\
\text { M }\end{array}$ \\
\hline Research supervisors: & $\begin{array}{l}\text { Professor Alta Kritzinger } \\
\text { Ms. Esedra Krüger }\end{array}$ \\
\hline Date: & April 2017 \\
\hline Title: & $\begin{array}{l}\text { Breastfeeding characteristics of late- } \\
\text { preterm infants in a kangaroo mother } \\
\text { care unit. }\end{array}$ \\
\hline
\end{tabular}

\section{Abstract}

Objective: To describe the breastfeeding characteristics of late-preterm infants (LPIs) in a kangaroo mother care unit (KMC).

Materials and methods: In a 20-bed KMC unit, the breastfeeding of 73 purposively-selected LPIs' (mean gestational age: 34.8 weeks) was observed once-off, using the Preterm Infant Breastfeeding Behavior Scale. Participants' mean age was 9.5 days, mean number of days in the unit was 3.1 days, and mean number of days breastfeeding was 7.5 days on observation.

Results: Only $13.7 \%$ of participants were directly breastfeeding without supplementary tube-feeding/cupfeeding and $86.3 \%$ received supplementary cupfeeding of expressed breast milk. Most participants did not exhibit obvious rooting (83.5\%) and although most latched-on (97.3\%), those who did, latched shallowly (93\%). The mean longest sucking burst was 18.8 (SD: 10.5) and approximately half the participants swallowed repeatedly (53.4\%). The mean breastfeeding session duration was 17.8 minutes but most participants breastfed less than 10 minutes $(76.7 \%)$. No statistically significant associations were found between chronological age and breastfeeding characteristics. A general trend towards more mature behaviors in participants breastfeeding for more days was present for 
many breastfeeding characteristics. More infants exhibited the most mature behavior for each breastfeeding characteristic when the environment was quiet, rather than noisy and disturbing, except for depth of latching (quiet: $0 \%$, disturbance: $15.2 \%)$.

Conclusion: LPIs in this sample presented with subtle, moderate breastfeeding difficulties, highlighting their need for breastfeeding support. Further research is required to examine the effect of KMC on breastfeeding in LPIs.

Key words: Late-preterm infants, breastfeeding characteristics, kangaroo mother care, rooting, latching, sucking, swallowing, breastfeeding experience, environmental influence, milk transfer 


\section{UNIVERSITY OF PRETORIA}

FACULTY OF HUMANITIES

DEPARTMENT OF SPEECH-LANGUAGE PATHOLOGY AND AUDIOLOGY

\section{DECLARATION}

Full Name:

Melissa Pike

Student Number:

11062500

Degree:

MASpeech-Language Pathology

Title of Dissertation: Breastfeeding characteristics of late-preterm infants in a kangaroo mother care unit.

I declare that this research report is my own original work. Where secondary material is used, this has been carefully acknowledged and referenced in accordance with university requirements.

I understand what plagiarism is and am aware of the University of Pretoria's policy in this regard. 


\section{Acknowledgements}

Thank you to each mother who allowed her infant to be included in this study, and to all healthcare professionals in the KMC unit at Kalafong Hospital, for willingly accepting us in their unit for data collection.

To Dr van Rooyen, thank you for your guidance in the beginning-stages of this study's research design. Your frequent help and support with information, and your expertise were much appreciated.

Thank you to Dion van Zyl, our statistician, for your invaluable guidance throughout the process: from the initial study design, to analysis of the data.

To Prof. Kritzinger and Mrs Krüger, for endless hours of marking, meetings and discussions, I thank you. Without you both, and your expertise, this study would not have been possible. And to Prof. Kritzinger, thank you especially for giving of your time to assist with data collection.

Endless thanks also go to all family and friends, for their support and understanding throughout this process.

And most importantly, thank you to my Heavenly Father, for being with me, every step of the way. 


\section{Table of Contents}

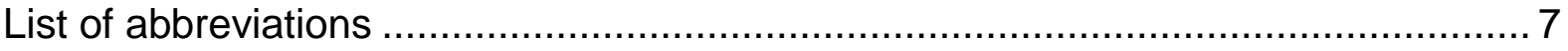

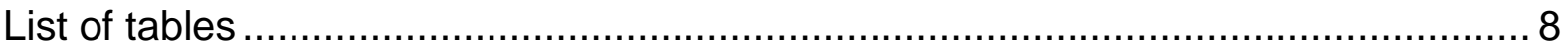

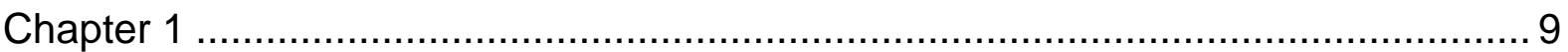

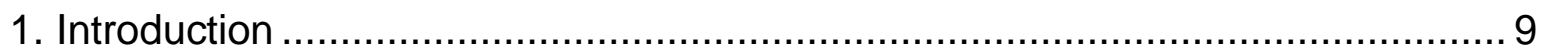

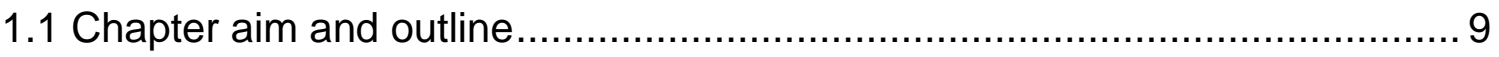

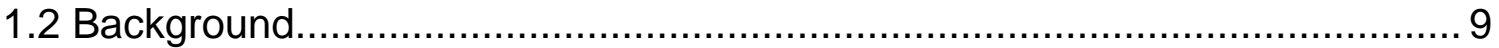

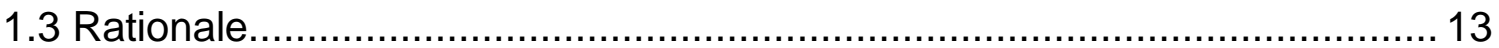

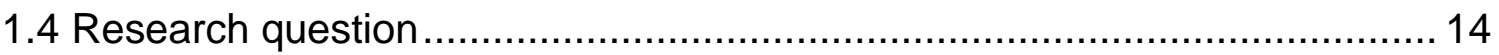

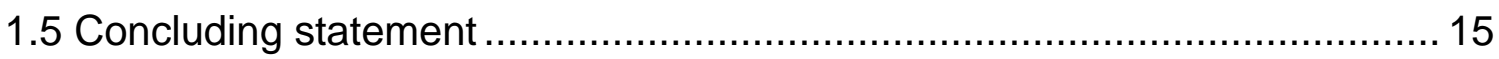

1.6 Terminology as used in dissertation ................................................... 15

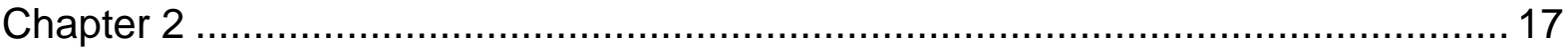

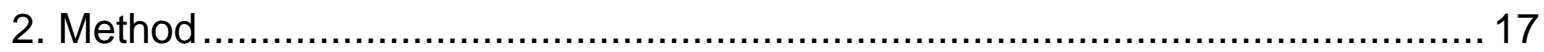

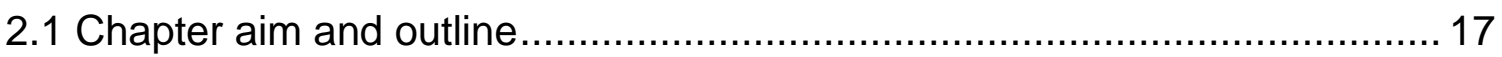

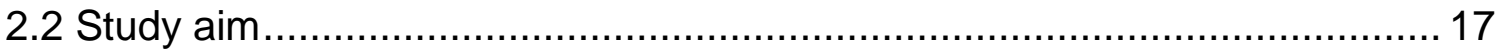

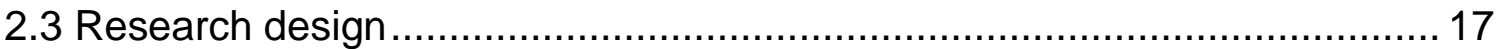

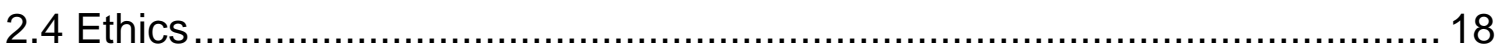

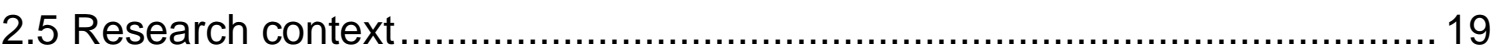

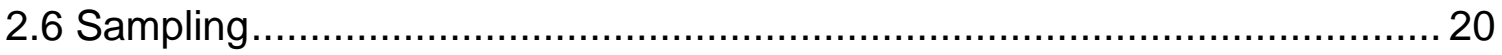

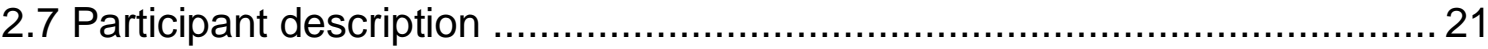

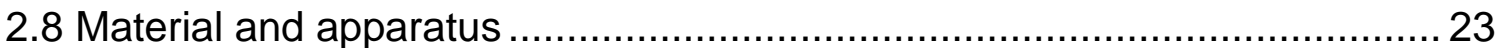

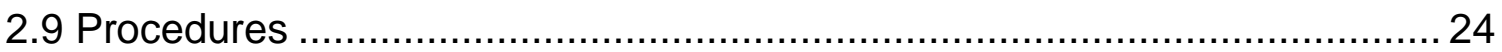

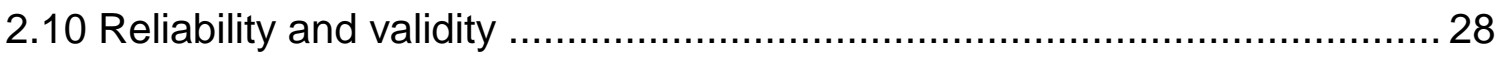

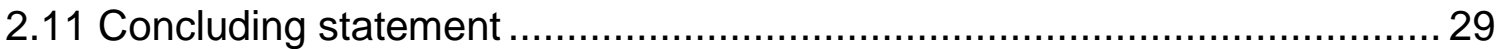


Chapter 3

3. Article 30

Chapter 4 54

4. Implications and conclusions 54

4.1 Chapter aim and outline 54

4.2 Implications 54

4.3 Limitations 64

4.4 Future research directions 65

4.5 Conclusion 66

References 69

Appendices

Appendix A: Permission letter from neonatologist in KMC unit

Appendix B: Faculty of Humanities ethical clearance

Appendix C: Faculty of Health Sciences ethical clearance

Appendix D: Ethical clearance Kalafong Hospital

Appendix E: English parent information and informed consent

Appendix F: Northern Sotho parent information and informed consent

Appendix G: isiZulu parent information and informed consent

Appendix $\mathrm{H}$ : Case history capturing checklist

Appendix I: Preterm Infant Breastfeeding Behavior Scale

Appendix J: Proof of article submission to Breastfeeding Medicine

Appendix K: Decision letter Breastfeeding Medicine 


\section{List of abbreviations}

American Speech-Language-Hearing Association (ASHA)

Baby Friendly Hospital Initiative (BFHI)

Bronchopulmonary dysplasia (BPD)

Gestational age (GA)

Human immunodeficiency virus (HIV)

International Business Machines Statistical Package for Social Sciences (IBM SPSS)

Inter-rater reliability (IRR)

Intra-uterine growth restriction (IUGR)

Kangaroo mother care (KMC)

Late-preterm infant (LPI)

Mean (M)

Neonatal intensive care unit (NICU)

Patent ductus arteriosus (PDA)

Post menstrual age (PMA)

Preterm Infant Breastfeeding Behavior Scale (PIBBS)

Respiratory distress syndrome (RDS)

Small for gestational age (SGA)

Speech-language therapist (SLT)

Standard deviation (SD)

Transient tachypnea of the newborn (TTN)

World-Health Organisation (WHO) 


\section{List of tables}

Table 1. Participant characteristics $(n=73)$

Table 2. IRR results for breastfeeding observations on the PIBBS by two SLTs $(n=22)$

Table 3. Analysis of IRR results for PIBBS test items that were less than very good, with agreed-upon criteria for future observations

Table 4. Participant and maternal characteristics $(n=73)$

Table 5. Breastfeeding characteristics according to chronological age-groups $(n=73)$

Table 6. Breastfeeding characteristics in relation to mean number of days breastfeeding $(n=73)$

Table 7. Participants' breastfeeding characteristics in relation to diagnosis of RDS $(\mathrm{n}=73)$

Table 8. General behaviour during breastfeeding

Table 9. Breastfeeding characteristics in relation to the environment $(n=73)$ 


\section{Chapter 1}

\section{Introduction}

\subsection{Chapter aim and outline}

The purpose of this chapter is to provide the reader with an overview of the current literature and previous research on late-preterm infants (LPIs) and their breastfeeding. It further serves to explain the reasons for conducting this study. The chapter begins with background information relevant to the study topic, and is followed by the study rationale and research question. The chapter ends with definitions of terminology used in this dissertation.

\subsection{Background}

LPIs have become a population of increased research interest since the particular vulnerabilities of these infants have been recognised. LPIs were traditionally treated as term infants due to their similarity in weight and apparent healthy appearance (Adamkin, 2006; Bird et al., 2010). However, studies have found LPIs still to be physiologically immature, and to have a higher risk of morbidity and mortality than term infants (Bird et al., 2010; Engle, Tomashek, \& Wallman, 2007; Horgan, 2015). Feeding difficulties are one of the complications found to be more prevalent in this population than in their term counterparts (Kuzniewicz, Parker, Schnake-Mahl, \& Escobar, 2013; Wang, Dorer, Fleming, \& Catlin, 2004).

Limited attention has been paid to the potential feeding difficulties in LPIs when compared to very- and moderately-preterm infants (Adamkin, 2006; Escobar, Clark, \& Greene, 2006). The lack of research is concerning as feeding difficulties are found to be one of the primary reasons for delays in the discharge of LPIs (Wang et al., 2004). Feeding difficulties in LPIs are also one of the most frequent reasons for hospital readmission following discharge (Kuzniewicz et al., 2013; Tomashek et al., 2006).

Research may be limited in this area because healthcare professionals may not expect feeding difficulties in LPIs, as the post menstrual age (PMA) of 33 to 34 
weeks has generally been used as the appropriate time to introduce oral feeds (Lau, Alagugurusamy, Schanler, Smith, \& Shulman, 2000). According to Bingham (2009), studies have shown a rhythmic nutritive suck in infants of 32 weeks GA. This also suggests that oral feeding in LPIs should be effective. Despite these developmental markers, literature suggests that as a group, LPIs may be at risk for feeding difficulties for several reasons (The Academy of Breastfeeding Medicine, 2011; Wang et al., 2004).

Firstly, LPIs may be at risk for feeding difficulties as they are still physiologically and neurologically immature (Shapiro-Mendoza \& Lackritz, 2012). Only 53\% of brain cortical matter is present at 34 weeks GA, with improvements in coordination of movement only occurring thereafter (Ludwig, 2007). Delaney and Arvedson (2008) state that only by 35 to 38 weeks GA is the nervous system sufficiently developed to be able to execute complex operations such as bottle-feeding and breastfeeding. Significant maturation and refinement of sucking, swallowing and breathing is still occurring during the third trimester of pregnancy (Medoff-Cooper, Bakewell-Sachs, Buus-Frank, \& Santa-Donato, 2006).

Secondly, feeding difficulties in LPIs have also been associated with various morbidities, such as hyperbilirubinaemia, hypoglycaemia, respiratory difficulties, hypernatraemia (increased serum sodium levels) and dehydration, which are commonly found in this population (Gouyon, lacobelli, Ferdynus, \& Bonsante, 2012; Kuzniewicz et al., 2013; Wang et al., 2004). These morbidities not only have a negative impact on feeding, but may also be worsened by poor feeding. This may result in a recurring cycle of difficulties in feeding, and poor nutritional and physiological status (Gouyon et al., 2012; Horgan, 2015; Ludwig, 2007; Meier, Furman, \& Degenhardt, 2007).

Thirdly, mothers of LPIs could experience delayed lactogenesis, which may result in unsuccessful breastfeeding, despite an infant's potential for effective oral feeding (Raju, Higgins, Stark, \& Leveno, 2006; Walker, 2008). This could contribute to decreased caloric intake by the infant (Radtke, 2012), which may in turn negatively impact on the supply and demand principle of breastfeeding, further contributing to inefficient breastfeeding (Radtke, 2012), and possibly jaundice or dehydration 
(Kuzniewicz et al., 2013; Meier et al., 2007). Jaundice and dehydration may contribute to the infant being fatigued, which again may result in decreased oral intake and a resultant decreased maternal milk supply (Meier et al., 2007).

Another reason LPIs may experience breastfeeding difficulties, is that they are also more likely than term infants to be separated from their mothers for medical investigations and treatments (Adamkin, 2006; Radtke, 2012; The Academy of Breastfeeding Medicine, 2011). This separation has been shown to have a negative impact on initiating and sustaining breastfeeding (Nyqvist et al., 2013). It is recommended that this separation be minimised and that skin-to-skin care, such as kangaroo mother care (KMC), be encouraged. Meier, Patel, Wright and Engstrom (2013) state that KMC is important to consider in the care of LPIs. This may be because early skin-to-skin contact is particularly important for promoting any or exclusive breastfeeding, and increasing breastfeeding duration (Goyal, Attanasio, \& Kozhimannil, 2014; Hake-Brooks \& Anderson, 2008; Mattsson, Funkquist, Wickström, Nyqvist, \& Volgsten, 2015). Skin-to-skin contact has also been found to be associated with earlier attainment of direct breastfeeding without the need for supplementary feeding methods such as cup-feeding and tube-feeding (Oras et al., 2016). KMC is also recommended for improving lactation (Lau, Hurst, Smith, \& Schanler, 2007).

With the increased recognition of the above-mentioned risks that LPIs have for poor feeding, studies have begun citing the presence of feeding difficulties in LPIs (Horgan, 2015; McDonald et al., 2013; Wang et al., 2004). A systematic review indicated $34 \%$ of LPIs versus $6.7 \%$ of full-term infants experienced feeding difficulties (Teune et al., 2011). Studies have shown LPIs to have an unsuccessful initial feed, lower breastfeeding initiation rates, decreased breastfeeding duration and lower exclusive breastfeeding rates than term infants (Goyal et al., 2014; Hackman, Alligood-Percoco, Martin, Zhu, \& Kjerulff, 2016; McDonald et al., 2013; Radtke, 2012; Rayfield, Oakley, \& Quigley, 2015; Zanardo et al., 2011). This is concerning, as the global standard for the optimal health and development of any child, is exclusive breastfeeding for at least the first six months of life ((World Health Organization [WHO], 2003a) and this includes LPIs (The Academy of Breastfeeding Medicine, 2011). 
Poor breastfeeding in LPIs is not only concerning because of the impact on the infant, but also due to its impact on the mother. A study by Demirci, Happ, Bogen, Albrecht and Cohen (2015) showed that mothers of LPIs experienced anxiety and fatigue when considering the discrepancy between their breastfeeding expectations and the difficulties that had been experienced when breastfeeding their LPIs. Lau et al. (2007) state that stress may affect lactation performance and thus maternal wellbeing is an important factor that may influence lactation performance. Poor breastfeeding may thus potentially contribute to greater anxiety in the mother and the resultant cycle of poor breastfeeding, infant physiological difficulties and limited lactation.

While the above-mentioned research suggests that breastfeeding difficulties are a factor to consider in LPIs, literature is limited regarding the specific breastfeeding characteristics that can be expected in LPIs. Some studies regarding specific feeding characteristics, such as sucking proficiency, were conducted using bottles (Gewolb \& Vice, 2006; Medoff-Cooper, Bilker, \& Kaplan, 2001). Nyqvist (2013) states that information regarding breastfeeding is often limited, and that deductions regarding infants' feeding are often based on their performance using bottles. However, several studies support the notion that bottle-feeding and breastfeeding entail different milk-release mechanisms (Furman \& Minich, 2004; Geddes, Kent, Mitoulas, \& Hartmann, 2008; Goldfield, Richardson, Lee, \& Margetts, 2006). Thus, the feeding characteristics studied using bottles cannot be used to explain breastfeeding.

Research focused on the characteristics of breastfeeding specifically, rather than bottle-feeding, tend to focus on moderately- and extremely-premature infants, once they reach 34 to 36 weeks PMA (Gewolb \& Vice, 2006; Nyqvist, Rubertsson, Ewald, \& Sjödén, 1996; Medoff-Cooper et al., 2001). Although these results can be used as a tentative guide for expectations of the breastfeeding characteristics a LPI might present with, the findings cannot be reliably generalised for two reasons. Firstly, lower GAs have been associated with increased feeding difficulties (Amaizu, Shulman, Schanler, \& Lau, 2008; Capilouto et al., 2014) and with a greater delay in achieving full oral feeds (White-Traut et al., 2013). Secondly, having more experience feeding orally, has been linked to enhanced sucking skills (Amaizu et al., 2008; Bingham, 2009). Infants born earlier may be more likely to have had more 
experience breastfeeding. Therefore, infants born before 34 weeks GA are expected to present with breastfeeding characteristics that differ from LPIs. The breastfeeding characteristics of two infants both observed at 36 weeks, one born at 36 weeks GA and the other at a younger GA, would be expected to differ.

A number of publications focused specifically on breastfeeding characteristics, and on infants with GAs falling in the late-preterm category (Adamkin, 2006; Horgan, 2015; Radtke, 2012; Walker, 2008). Factors such as difficulties latching, decreased levels of alertness and endurance, low muscle tone due to immaturity, weakness, difficulties sucking, difficulties swallowing, and tendencies to become overstimulated during feeding were highlighted as possible reasons for the increased prevalence of breastfeeding difficulties in LPIs (Adamkin, 2006; Cleaveland, 2010; Horgan, 2015; Radtke, 2012; Walker, 2008). These five publications that highlighted specific breastfeeding characteristics in LPIs, although valuable, appear not to be based on original research, but rather on clinical experience. Radtke (2012) agreed with this observation, as she stated in her review on breastfeeding in LPIs, that the conclusions of the review were of necessity, primarily based on expert opinion and experience, due to the lack of research in this area. These studies may thus not represent a high level of evidence.

\subsection{Rationale}

It is clear from the literature reviewed that breastfeeding difficulties are a reality in LPIs. However, original research is limited for the specific breastfeeding characteristics of LPIs. The literature appears either to be vague regarding the type of feeding difficulties or has focused on bottle-feeding. The focus tends to be on infants born before 34 weeks GA, following their development until they reach 34 weeks PMA and older. Publications focused on the specific breastfeeding characteristics of LPIs, appear to be based on clinical experience, rather than on original research. The drive for evidence-based research necessitates that further studies be carried out in this area. In addition, limited research is available specific to LPIs' breastfeeding in KMC, an intervention known to promote breastfeeding (Mahmood, Jamal, \& Khan, 2011). 
Further information regarding the characteristics of breastfeeding difficulties in this population may be valuable to speech-language therapists (SLTs), dieticians, nurses and medical doctors working in the KMC unit. SLTs provide feeding intervention in the KMC unit, and it would be valuable for these professionals to have more information regarding the breastfeeding characteristics in a population of infants that may typically be excluded from intervention, due to their expected ability to breastfeed successfully.

As successful feeding and weight-gain are two of the main criteria for discharge from the KMC unit (Van Rooyen, Pullen, Pattinson, \& Delport, 2002; Van Rooyen, 2016), this information may be helpful in the early identification of- and intervention for the possible breastfeeding difficulties that may place LPIs at risk for delayed discharge and hospital readmission. Further detailed descriptions of breastfeeding may assist in the provision of individualised breastfeeding support for this population of LPIs. This individualised support and early intervention may decrease the risk for maternal psychological distress that may be associated with poor feeding. Early intervention may also assist in preventing the negative cyclic implications of poor breastfeeding on milk intake, vulnerable infant physiological status, maternal anxiety and maternal milk supply. Breastfeeding has also been shown to enhance mother-infant attachment and bonding (Kaur \& Kumar, 2011). Potentially poor bonding and attachment as a result of difficulty breastfeeding, may also be avoided with the early identification and management of breastfeeding difficulties.

Establishing successful breastfeeding is not only important for maternal support, bonding, and early discharge, but exclusive breastfeeding is also the global standard for optimal child health and development, including for those infants' mothers who have human immunodeficiency virus [HIV] (WHO, 2012). Early initiation of breastfeeding is also one of the most important aspects for decreasing child mortality (WHO, 2012). Having highlighted the benefits of further research on LPIs' specific breastfeeding characteristics, the following research question was formulated.

\subsection{Research question}

What are the breastfeeding characteristics of LPIs in a KMC unit? 


\subsection{Concluding statement}

This introduction highlighted the research surrounding the topic of breastfeeding in LPIs in a KMC unit, and has served to summarise the rationale and purpose of the research study conducted.

\subsection{Terminology as used in dissertation}

Breastfeeding directly: This refers to infants feeding directly at the breast, rather than receiving breast milk by alternative means, such as cup-feeding or tubefeeding.

Breastfeeding exclusively: This refers to infants who receive breast milk only, with no artificial milk. Exclusive breastfeeding refers to any feeding method by which breast milk is provided, including direct breastfeeding, tube-feeding and cup-feeding.

Chronological age: The time elapsed after birth, usually described in days, weeks, months or years (American Academy of Pediatrics, 2004).

Feeding difficulties: Difficulties in anticipating food, readying oneself for food, placement of food in the mouth, management of the bolus, transferring the bolus into the pharynx, as well as the interaction between the infant and mother (Delaney \& Arvedson, 2008).

Gestational age: The time between the first day of the last normal menstrual period, and the day of delivery, and is typically used to describe the age of the newborn infant on the day of delivery (American Academy of Pediatrics, 2004).

Kangaroo mother care: This is an evidence-based intervention, in which early skinto-skin contact between the mother and infant is practiced, exclusive breastfeeding is considered ideal, early discharge of small infants is made possible, and support for the infant and mother post-discharge is emphasised (WHO, 2003b). Although this is an intervention specifically for preterm, low-birth weight infants, it can be practiced with term infants too (WHO, 2003b). Both continuous, and intermittent KMC were practiced in the $\mathrm{KMC}$ unit during the data collection period: 
Continuous KMC: In the KMC unit, continuous KMC ideally entails skin-to-skin care throughout the day and night. The infant in only removed from the mother's chest during feeding and when the mother showers. (Van Rooyen, 2016)

Intermittent KMC: Skin-to-skin care is practiced throughout the night as the mother sleeps. During the day, the baby is kept on the mother's chest for as often as oxygen therapy allows. (Van Rooyen, 2016)

Late-preterm infants: Infants with GAs between 34 weeks, zero days and 36 weeks and six days (Engle et al., 2007).

Post menstrual age: Describes the amount of time between the first day of the last menstrual period and the day of delivery (GA), in addition to the amount of time that has elapsed after birth [chronological age] (American Academy of Pediatrics, 2004). 


\section{Chapter 2}

\section{Method}

\subsection{Chapter aim and outline}

Chapter two serves to provide in-depth and detailed information regarding the research process which was followed in conducting the present study. The chapter begins by explaining the study aim, and is followed by the research design, ethical principles adhered to, description of the research context, sampling techniques, participant description as well as materials used and methods followed. The procedures followed are also discussed, as well as the approach to data analysis and descriptions of how reliability and validity were ensured in this study.

\subsection{Study aim}

The aim of this research project was to describe the breastfeeding characteristics of LPIs in a KMC unit.

\subsection{Research design}

A prospective, quantitative, descriptive and correlational research design was employed. A descriptive design was selected because descriptive research is used to identify the characteristics of an observed aspect (Leedy \& Ormrod, 2014). In this case, it was the identification of breastfeeding characteristics in LPIs in a specific setting.

This research design was that of an observational study, which entailed a once-off observation and thus took on the form of a cross-sectional study. The breastfeeding characteristics of LPIs were systematically observed to obtain information regarding this aspect, which is in accordance with the definition of an observational study (Leedy \& Ormrod, 2014). These observations were then summarised using various statistical indexes to draw inferences about the specific population, as is typical of an observational study. Being able to describe the characteristics of a sample of the larger population, may allow cautious generalisation of these characteristics to the larger population (Leedy \& Ormrod, 2014). This study included a moderately-sized 
sample of LPIs in a KMC unit, thus generalisation to the larger population should be cautious, as a larger sample size may have been more generalisable.

A correlational research design is used when determining whether or not a relationship exists between variables (Nelson, 2017). In this study, the correlational design was used for determining whether or not a relationship existed between breastfeeding characteristics and chronological age-groups of the participants.

\subsection{Ethics}

Permission was obtained from the neonatologist working in the KMC unit in order to conduct research in the unit (Appendix A). Ethical clearance was granted by the University of Pretoria's Faculty of Humanities (Appendix B) and the Faculty of Health Sciences (Appendix C) prior to data collection. Ethical clearance was also granted by the academic hospital's ethics committee (Appendix D) in order to conduct the study.

The following ethical principles were adhered to in the study: voluntary and informed participation, protection from harm, the right to privacy, research integrity, accurately reporting information and proper attribution of ideas. Voluntary informed consent was obtained from the mothers of all participants after providing them with written and verbal information regarding the project (Appendix E). An interpreter was used on two occasions when it appeared that the mother had not fully understood the researcher. The interpreters were also required to sign the informed consent document. The informed consent document was translated into Northern Sotho (Appendix F) and isiZulu (Appendix G). This aspect ensured adherence to the ethical principle of voluntary and informed participation, or allowing the participant to make their decisions freely and independently once they have been informed regarding the nature of the study (Leedy \& Ormrod, 2014).

The study incorporated observation of a normal breastfeeding session, which is the least invasive method of studying breastfeeding (Nyqvist et al., 1996). To ensure that the ethical principle of protection from harm (Nelson, 2017) was adhered to, only infants declared fit to attempt breastfeeding by the doctor in the ward were observed. It was decided that if it was deemed unsafe for an infant to continue the breastfeeding session, the feeding session would be discontinued. It was also 
decided that infants who were thought to require feeding intervention by an SLT, would be referred to the SLT working at the hospital. No infant in the study was deemed unfit to complete a breastfeeding session, or to have breastfeeding difficulties considered unsafe or severe enough to warrant referral to an SLT.

The confidentiality of patient records was maintained by keeping a spread sheet on a password-protected computer, adhering to the ethical principle of the right to privacy (Leedy \& Ormrod, 2014; Nelson, 2017). Only those directly involved in capturing, analysing and interpreting the data had access to patient records, namely the author of the dissertation, the research supervisors, the statistician and the statistician's assistant. The data will be kept in hard-copy for a period of 15 years, in accordance with the University of Pretoria's guidelines. The data is stored at the Department of Speech-Language Pathology and Audiology, in a secure room.

The results were reported honestly and are in the process of being disseminated to the academic community. Every attempt was made to accurately reflect what the results of the study indicated, as is in accordance with the ethical principle of research integrity and accurate reporting of information (Nelson, 2017). In reporting these findings, every attempt has been made to avoid plagiarism, attempting to adhere to the principle of proper attribution of ideas (Nelson, 2017).

\subsection{Research context}

Data collection took place in the KMC unit at a regional academic hospital in Pretoria. The unit is able to accommodate 20 mother-infant pairs, who remain in the unit overnight. The primary function of the unit is to accept healthy, low-birth weight and premature infants from high care or the neonatal intensive care unit (NICU), as soon as oral feeding has been established. The unit also accepts full-term infants who are experiencing feeding difficulties or who require phototherapy. The majority of infants are transferred from the hospital's NICU. The KMC unit can accommodate infants who are receiving oxygen via nasal cannula. When infants are oxygendependent, they receive intermittent $\mathrm{KMC}$, beginning with continuous $\mathrm{KMC}$ as soon as they are no longer oxygen-dependent. Infants can be discharged from the unit if their weight is above $1550 \mathrm{~g}$, if infants are breastfeeding well, and if they have been 
oxygen independent for three to four days. The unit also accommodates a weekly follow-up clinic for infants discharged from the KMC unit. (Van Rooyen, 2016)

In the KMC unit, direct breastfeeding is considered the best option (Van Rooyen, 2017b). However, when infants are experiencing difficulties with direct breastfeeding, tube-feeding or cup-feeding are provided, while they are encouraged to suckle at the breast (Van Rooyen, 2017b). Top-up cup-feeding is often used as a transition between tube-feeding and direct breastfeeding, or if direct breastfeeding is not yet fully established to ensure the intake of specific volumes at each feeding session (Van Rooyen, 2017b). Bottle-feeding is not permitted, as the Baby Friendly Hospital Initiative [BFHI] (WHO, 2009) is adhered to in the ward. Expressed breast milk will often be fortified with the supplement FM 85 when an infant is on $100 \mathrm{ml}$ oral feeds per kilogram weight (Van Rooyen, 2017b). Donor breast milk is made available for mothers who are not able to provide their own breast milk for their infants (Van Rooyen, 2017b). HIV exposed infants are encouraged to breastfeed directly as most mothers diagnosed with HIV are on antiretroviral drugs and exposed infants immediately receive Nevirapine. Pasteurisation of expressed breast milk will only take place if the mother has a high HIV viral load or is resistant to the first line of antiretroviral drugs (Van Rooyen, 2017b). If a mother reports breastfeeding difficulties, the nursing staff will review the situation and support the mother. If breastfeeding difficulties continue, the dietician, milk manager and possibly the SLT will be contacted to evaluate the infant's feeding, providing further support (Van Rooyen, 2017a).

\subsection{Sampling}

Non-probability, convenient sampling was used in order to purposively select 73 participants, the largest number possible within the available time-frame for this particular master's study. Criteria for inclusion into the study were that each participant should fall into the category of being a LPI, regardless of chronological age, and should be in the KMC unit. In the KMC unit, GA is determined using the New Ballard Score (Ballard et al., 1991). The New Ballard Score is recorded by a doctor, based on an examination of the neuromuscular and physical characteristics of the newborn infant. This is considered less reliable than determining GA by means 
of antenatal ultrasonography and menstrual history (Ballard et al., 1991). However, according to the neonatologist in the KMC ward, antenatal sonars are not consistently conducted and mothers are often unsure of their menstrual history (Van Rooyen, 2017a). This motivated for the use of the New Ballard Score (Ballard et al., 1991).

Any infant who was not directly breastfeeding was excluded. If an infant was not directly breastfeeding due to his or her poor feeding skills, the mother was asked to attempt breastfeeding for the single observation session, after obtaining permission from the doctor to do so. If the infant was not directly breastfeeding for maternal reasons, for example, the mother's high HIV viral load, the infant was excluded. Participants with morbidities were not excluded, in order to provide an accurate and holistic picture of breastfeeding characteristics of LPIs in a KMC unit.

\subsection{Participant description}

Of the 73 participants, $48(66 \%)$ were male. A total of $28(38.4 \%)$ participants were 34 weeks GA, 28 (38.4\%) were 35 weeks GA and 17(23.2\%) were 36 weeks GA. The mean GA of participants was 34.8 weeks GA. Participants' mothers were on average 29 years old (SD: 7.2, Range: 16-43), with 57\% having at least a secondary level of education. A total of $64 \%$ of mothers were living in informal housing in the hospital's surrounding areas, as well as in informal housing in neighbouring countries, such as Zimbabwe. Additional participant characteristics are depicted in Table 1.

Table 1. Participant characteristics $(n=73)$

\begin{tabular}{llllll}
\hline Characteristic & Mean & $\begin{array}{l}\text { Standard } \\
\text { deviation }\end{array}$ & Minimum & Maximum & Skewness \\
\hline Birth weight $(\mathrm{kg})^{*}$ & 2.1 & 0.4 & 1.4 & 4.1 & 1.5 \\
Current weight $(\mathrm{kg})$ & 2.1 & 0.4 & 1.4 & 3.9 & 1.5 \\
NICU stay duration (days) & 6.0 & 7.6 & 0 & 41 & 3.0 \\
KMC stay duration (days) & 3.1 & 2.6 & 1 & 14 & 2.2 \\
Chronological age (days) & 9.5 & 9.1 & 2 & 55 & 2.9 \\
Breastfeeding duration (days) & 7.5 & 6.7 & 0 & 43 & 2.8 \\
\hline
\end{tabular}

${ }^{*} n=72$ due to one missing value

Table 1 indicates that birth weight and current weight are fairly consistent amongst 
participants. However, there is a relatively large SD and range for NICU and KMC stay duration, as well as chronological age and breastfeeding duration. This is due to the KMC unit's admission criteria that an infant should be healthy and should typically have established oral feeding prior to admission into the unit. As a result, infants may experience a prolonged NICU stay prior to admission in the KMC unit, contributing to several participants having relatively high chronological ages, and varying KMC stay duration and breastfeeding duration. The positive skewness of these variables indicates that the mass of the distribution of participants is towards shorter NICU stays and lower chronological ages. Thus, although most participants did not have long NICU stays, and high chronological ages, there were a small number of participants who had prolonged NICU stays, and a resultant higher chronological age at the time of data collection.

Another reason for the variable chronological age and number of days in the NICU may be due to a number participants presenting with additional risk- and medical factors, which could potentially influence the NICU stay duration and subsequent chronological age at the time of data collection. These include being one of a twin (35.6\%), birth by caesarean section (61.6\%), HIV exposure $(27.4 \%)$, bronchopulmonary dysplasia (BPD) (1.4\%), transient tachypnea of the newborn (TTN) (19.2\%), patent ductus arteriosus (PDA) (13.7\%), respiratory distress syndrome (RDS) (46.6\%), small for gestational age/intra-uterine growth restriction (SGA/IUGR) (31.5\%), hyperbilirubinaemia (67.1\%), congenital disorders (6.8\%) and craniofacial anomalies (6.8\%). Participants with these conditions may be ill, and thus be in the NICU without directly breastfeeding for an extended period of time.

The mean length of stay of an infant in the KMC unit is 13.3 days, according to the 10 year KMC audit of the academic hospital at which data collection took place (Van Rooyen, 2009). This is longer than the mean length of stay (3.1 days) of the participants in this study. This may be due to the attempt on the part of the researchers of the present study to recruit as many participants as possible prior to their discharge. This may have resulted in early assessments during the infants' stay in the KMC unit. Furthermore, the 10 year audit included younger, more preterm 
infants in their sample than the present study did. An extremely preterm infant would be expected to stay longer in the KMC unit than a LPI.

\subsection{Material and apparatus}

2.8.1 Materials. Two checklists were used. The use of a checklist is one technique for assessing and quantifying more complex aspects of descriptive research (Leedy \& Ormrod, 2014), such as feeding behaviour. The first checklist was used to record information pertaining to the infants' prenatal history, family circumstances, perinatal history and other potential risk factors (Appendix $\mathrm{H}$ ). The document is based on the Risk Assessment, which was developed and tested in a master's study and was based on a literature overview of risks associated with communication delay and dysphagia (Kritzinger, 1994). It was later used in a study for identifying risk factors in a primary healthcare community (Claassen, Pieterse, Van der Linde, Kruger, \& Vinck, 2016). A combination of medical record review and a brief interview with the mother of the participant were used to complete this document.

The outcomes measure was the Preterm Infant Breastfeeding Behavior Scale (Nyqvist et al., 1996) (Appendix I). This is a validated tool, which is designed to be used by mothers and healthcare professionals to guide observations of preterm infants' breastfeeding behaviour (Nyqvist et al., 1996). The PIBBS was found to have a high inter-rater reliability (IRR) between nurses using the tool (Nyqvist et al., 1996; Nyqvist, 2013) and has been used frequently in previous research (Nyqvist, 2005; Nyqvist, Sjoden, \& Ewald, 1999; Radzyminski, 2005). It has been listed by Arvedson (2008) as a tool that can be used for assessing paediatric feeding and swallowing in breastfeeding infants. It is a comprehensive checklist for recording a number of aspects related to breastfeeding, including rooting, how much of the breast was inside the baby's mouth, latching-on and staying fixed to the breast, sucking, the length of the longest sucking burst, swallowing, the infant's general behaviour, the mother's perception of the letdown reflex, the presence of breast problems, as well as the influence of the immediate physical environment on breastfeeding. For the sake of clarity, in the present study, the test item 'how much of the breast was inside the baby's mouth' is referred to as depth of latching, and 'latching-on and staying 
fixed to the breast' is referred to as latching-duration. The definitions for the aspects to be observed, were based on literature and refined by clinical observations in a research study (Nyqvist et al., 1996). The tool sets out maturational steps for each breastfeeding characteristic, from immature, which may be observed in a very premature infant, to mature behaviours, which may be exhibited in a term infant. The level of maturity is measured in interval scales, for example, from no rooting, to some rooting and obvious rooting. The tool also makes use of ratio scales, such as counting the number of sucks or measuring the length of time the participant latches onto the breast.

2.8.2. Apparatus. The stopwatch application on Apple iPhones was used for recording length of latching time, and the length of time that each infant was held for direct breastfeeding.

\subsection{Procedures}

2.9.1. Data collection. The PIBBS was completed by the researcher and a second rater through observation of a direct breastfeeding session and by questioning the mother. It was not completed by the mother, as intended by the authors of the tool. The reason behind this adaptation was that mothers in the unit were not firstlanguage English speakers and able to complete the checklist independently. This tool was tested in the KMC unit of the same academic hospital as where the present study was conducted, in an undergraduate study (Havenga \& Joubert, 2015). The tool was found to be applicable for use in the unit, with the exception that mothers were unable to use the scale independently due to language barriers.

At the onset of data collection for analysis of breastfeeding characteristics, tests for IRR for the two raters using the PIBBS took place. The two raters were qualified SLTs registered with the Health Professions Council of South Africa. The first three participants' breastfeeding sessions were jointly observed by both raters and functioned as training sessions, allowing for discussion and consensus regarding observations and scoring. The following 22 participants' breastfeeding sessions were also jointly observed by both raters, but without discussion, and tests for IRR were conducted. Statistical testing for IRR revealed varying levels of IRR for test items 
(See Table 2). Cohen's Kappa values ranged from poor $(<0.40)$, to fair to good $(0.41$ to 0.75 ), and very good (0.75 to 1.0) (Fleiss, Levin, \& Paik, 2003). As a result of these varying levels of IRR, all 22 participants' results were jointly reviewed and discussed by both raters, as well as an additional SLT familiar with the tool. A consensus was then reached regarding the first 22 participants' results for all PIBBS test items for use in future analysis of data. Reasons behind poor, and fair to good IRR were discussed and criteria for further observations by only one rater were then determined to ensure accurate future observations (See Table 3).

Table 2. IRR results for breastfeeding observations on the PIBBS by two SLTs $(n=22)$

\begin{tabular}{lll}
\hline Observation item & \% agreement & Cohen's Kappa \\
\hline Rooting & 50 & 0.29 \\
Depth of latching & 62 & 0.36 \\
Latching-on & 76 & 0.46 \\
Sucking & 85 & 0.74 \\
Swallowing & 67 & 0.37 \\
Closed eyes, no body movements & 95 & 0.88 \\
Drowsy, open eyes, but heavy-lidded & 95 & 0.86 \\
Open eyes, dull and glazed look & 100 & 1.00 \\
Eyes wide open, looked tense and afraid & 100 & Variables constant \\
Eyes wide open, achieved eye contact & 100 & Variables constant \\
Closed eyes, active movement & 86 & 0.58 \\
Open eyes, active movements & 100 & 1.00 \\
Cried, fussed audibly & 86 & 0.70 \\
Letdown reflex & 86 & -0.07 \\
Length of time held for breastfeeding & 45 & 0.37 \\
Breast problems & 100 & Variables constant \\
Influence of environment & 41 & 0.48 \\
\hline
\end{tabular}

Achieving good IRR can be difficult, particularly in observational studies. Factors that may be difficult to observe, possibly due to poor visibility as discussed, can also contribute to lower IRR (Hallgren, 2012). Nyqvist et al. (1996), in the development of the PIBBS, also highlighted poor visibility as a difficulty when observing infants during breastfeeding. In future, in order to limit the impact of these factors on test scoring, a longer and more intensive period of training should be undertaken in the use of the PIBBS. In this way, subjectivity when scoring the tool may be lessened. Tools should be scored in an environment where both raters have clear view of the infant's mouth and throat, as limited space in the KMC unit impacted on this aspect. 
Table 3. Analysis of IRR results for PIBBS test items that were less than very good (Cohen's Kappa $<0.75)$, with agreed-upon criteria for future observations

\begin{tabular}{|c|c|c|}
\hline Test item & Possible reason for variation & Criteria for future observation \\
\hline \multicolumn{3}{|c|}{ Items with poor levels of agreement (Cohen's Kappa <0.40) } \\
\hline Rooting & $\begin{array}{l}\text { Differences arose as one observer took note } \\
\text { of rooting at first contact with the breast, and } \\
\text { the other, throughout the breastfeeding } \\
\text { session. }\end{array}$ & $\begin{array}{l}\text { Rooting should be recorded as observed } \\
\text { at the infant's first contact with the } \\
\text { breast. No rooting behaviours thereafter } \\
\text { should be taken into account. }\end{array}$ \\
\hline Depth of latching & $\begin{array}{l}\text { Differing understandings of how much is } \\
\text { considered "some" of the areola in the } \\
\text { infant's mouth. }\end{array}$ & $\begin{array}{l}\text { A greater amount of the areola should } \\
\text { be in the infant's mouth, before scoring } \\
\text { that "some" of the areola is in the } \\
\text { infant's mouth. }\end{array}$ \\
\hline Swallowing & $\begin{array}{l}\text { Differences were determined to be due to } \\
\text { poorer visibility of the infant's throat, when } \\
\text { two observers are attempting to view one } \\
\text { assessment session }\end{array}$ & $\begin{array}{l}\text { The observer should ensure clear } \\
\text { visibility of the infant's throat when } \\
\text { observing the session. }\end{array}$ \\
\hline Letdown reflex & $\begin{array}{l}\text { Although Cohen's Kappa values were } \\
\text { considered poor, percentage agreement for } \\
\text { this item was } 86 \% \text {, as a result of very few } \\
\text { mothers not experiencing the letdown reflex. }\end{array}$ & $\begin{array}{l}\text { The observer should continue to confirm } \\
\text { with the mother whether or not the } \\
\text { letdown reflex was experienced, and } \\
\text { whether it was experienced at the } \\
\text { beginning or during the feeding session. }\end{array}$ \\
\hline $\begin{array}{l}\text { Length of time held for } \\
\text { breastfeeding }\end{array}$ & $\begin{array}{l}\text { Differences may have been present as a } \\
\text { result of ambiguity in terms of when the } \\
\text { session had started or ended. For example, a } \\
\text { mother would not always clearly indicate if } \\
\text { the session had been completed, or if she } \\
\text { would be reattempting to establish a latch } \\
\text { within a } 30 \text { minute time period. Additionally, } \\
\text { times recorded by raters were generally one } \\
\text { to two minutes appart, which would be } \\
\text { statistically significant, but not clinically } \\
\text { significant. }\end{array}$ & $\begin{array}{l}\text { The observer should clarify specifically } \\
\text { with the mother whether the session had } \\
\text { ended or not. }\end{array}$ \\
\hline
\end{tabular}

Items with fair to good levels of agreement (Cohen's Kappa: 0.41 to 0.75)

Latching-on Differences may have arisen as one or two short latching durations, may have been missed by either observer due to note-taking or poorer visibility when one session is observed by two raters.

Sucking Cohen's Kappa value of 0.74 falls just below the category of very good (0.75). Minor differences may have arisen as occasional sucking bursts were missed during notetaking.

Closed eyes, active movement Typically similar observations were made in general behaviour items, but occasionally one rater would mark an additional behaviour noted. This may have occurred at times when the other rater was taking note of another aspect of the assessment. Behaviours may alter rapidly within a breastfeeding session. Influence of environment
Differences appeared to arise as a result of different points of reference to noise. One rater compared the level of noise to that of a quiet home environment. The other, who worked frequently in the unit, compared the noise to levels of noise typically present in the unit.
Note-taking should be kept to a minimum and clear visibility of the infant's face should be ensured.

Note-taking should be kept to the absolute minimum, to avoid missing aspects of the observation.

The observer should minimise notetaking where possible, ensuring behaviours are not missed.

The observer should compare noise to the "ideal", a quiet home environment. 
Despite these varying IRR results, one should also consider the clinical value of varying levels of IRR for each item. For example, one rater may have recorded that an infant exhibited no licking and no sucking, and the other recorded that the infant exhibited some licking, but no sucking. While these differences in scoring would impact on IRR, the clinical significance of this difference may not be great. Both of these behaviours would indicate an infant who is not successfully sucking.

For joint observations, as well as continued individual observations by one rater, once informed consent had been obtained, medical records were reviewed and an interview carried out with the participants' mothers in order to complete the case history. One complete direct breastfeeding session was observed. As both cupfeeding and direct breastfeeding take place at a typical feeding time, the mothers were requested to cup-feed after their direct breastfeeding session, in order to prevent satiety and other factors from impacting on the direct breastfeeding session.

A direct breastfeeding session was defined as beginning when the infant made oral contact with the breast, and ending when oral contact with the breast ceased, or after a pause of 30 minutes or more following cessation of activity directed towards the breast, as recommended by Nyqvist et al. (1996). This observation took place at any one of the normal three-hourly feeding times adhered to in the unit. The observer would sit or stand in a position where the participant's face was most clearly visible. Notes were taken during the direct breastfeeding session, and the scale completed immediately following the completion of the session. Items requiring specific time measurements were recorded with a stopwatch by the observers.

2.9.2. Data analysis. All data recorded in the data collection forms were captured into an electronic database before being analysed using IBM SPSS (Version 24). This was done in collaboration with a statistician. When assessing for IRR, the Cohen's Kappa Measure of Agreement was used in order to determine precision between two raters completing the checklist during simultaneous observation of the direct breastfeeding session. The purpose of Cohen's Kappa is to determine the level of agreement between raters, taking into account the agreement that would occur simply by chance (Hallgren, 2012). For analysis of specific breastfeeding 
characteristics, descriptive statistics were calculated in order to describe the breastfeeding characteristics present in the sample population. This involved making use of summary statistics, such as basic frequencies; measures of central tendency, such as mean, median and mode; as well as measures of variability, such as standard deviation. Kurtosis and skewness were also determined. All of these statistics are used in order to describe data in a sample (Leedy \& Ormrod, 2014).

Chi-squared test and the Fisher's exact test procedures were used to determine if statistically significant differences and associations existed between breastfeeding characteristics and chronological age-groups (Reinard, 2006). Given the ordinal nature of the data, the Spearman correlation coefficient was calculated (Reinard, 2006). A level of significance of 0.05 was determined to be statistically significant.

\subsection{Reliability and validity}

2.10.1. Reliability. Reliability was ensured through various means. Firstly, training in the use of the PIBBS took place between the two raters. IRR was then determined. Results were then discussed and consensus reached and further, specific guidelines were then established for further observations. Once clear guidelines had been established, only one rater observed the breastfeeding sessions, ensuring consistency across observations. Additionally, all participants were recruited from the same KMC unit, and thus context remained consistent. These methods served to contribute to increased reliability during data collection. Intra-rater reliability was not determined, given the likelihood that one participants' behaviour may alter from one breastfeeding session to the next.

2.10.2. Validity. Validity was ensured in a variety of ways. This included the use of as large a sample size as possible, within the available time-frame for this specific master's study. When selecting the outcomes measure, the PIBBS, every effort was made to select a validated tool, used frequently in research on preterm infants. Data were entered and analysed in collaboration with a statistician, ensuring the accurate analysis of results. Data entries were additionally checked by accounting for missing 
values, and checking for correlations between numbers, which mutually exclude oneanother, or were expected to impact on one another.

\subsection{Concluding statement}

This chapter has indicated the process and procedures used in carrying out the present study. The method used, was designed with the purpose of attempting to investigate the study topic, as accurately as possible. 


\section{Chapter 3}

\section{Article}

The following article was submitted on 27 March 2017 to the journal, Breastfeeding Medicine, for review (Appendix $\mathrm{J}$ ) and has been provisionally accepted for publication. Formatting and style differ from that of this dissertation, in an attempt to adhere strictly to the journal's guidelines for articles submitted for publication.

\section{Abstract}

Objective: To describe the breastfeeding characteristics of late-preterm infants (LPIs) in a kangaroo mother care (KMC) unit.

Materials and methods: In a 20-bed KMC unit, the breastfeeding of 73 purposivelyselected LPIs' (mean gestational age: 34.8 weeks) was observed once-off, using the Preterm Infant Breastfeeding Behavior Scale. Participants' mean age was 9.5 days, mean number of days in the unit was 3.1 days, and mean number of days breastfeeding was 7.5 on observation.

Results: Only $13.7 \%$ of participants were directly breastfeeding without supplementary naso- or orogastric feeding/cupfeeding and $86.3 \%$ received supplementary cup-feeding of expressed breast milk. Most participants did not exhibit obvious rooting (83.5\%) and although most latched-on (97.3\%), those who did, latched shallowly (93\%). The mean longest sucking burst was 18.8 (SD: 10.5) and approximately half the participants swallowed repeatedly (53.4\%). The mean breastfeeding session duration was 17.8 minutes but most participants breastfed less than 10 minutes (76.7\%). No statistically significant associations were found between chronological age and breastfeeding characteristics. A general trend towards more mature behaviors in participants breastfeeding for more days was 
present for many breastfeeding characteristics. More infants exhibited the most mature behavior for each breastfeeding characteristic when the environment was quiet, rather than noisy and disturbing, except for depth of latching (quiet: $0 \%$, disturbance: $15.2 \%)$.

Conclusion: LPIs in this sample presented with subtle breastfeeding difficulties, highlighting their need for breastfeeding support. Further research is required to examine the effect of KMC on breastfeeding in LPIs.

Keywords: Breastfeeding characteristics; kangaroo mother care; late-preterm infants

\section{List of acronyms and abbreviations:}

Baby Friendly Hospital Initiative (BFHI)

Gestational age (GA)

Human immunodeficiency virus (HIV)

International Business Machines Statistical Package for Social Sciences (IBM SPSS) Inter-rater reliability $(\mathrm{IRR})$

Kangaroo Mother Care (KMC)

Late-preterm infant (LPI)

Mean (M)

Neonatal intensive care unit (NICU)

Post menstrual age (PMA) 
Preterm Infant Breastfeeding Behavior Scale (PIBBS)

Speech-language therapist (SLT)

Standard deviation (SD)

\section{Introduction}

Late-preterm infants (LPIs), or those born between 34 and 36 weeks and six days gestational age (GA), have become a population of increased research interest since their vulnerabilities have been recognized. Feeding difficulties are one of the complications found to be more prevalent in this population than in term infants, ${ }^{1}$ and are one of the primary reasons for delays in discharge, and hospital readmission of these infants. ${ }^{1,2}$

LPIs may be at risk for feeding difficulties for several reasons. ${ }^{3}$ Firstly, LPIs are still physiologically and neurologically immature. ${ }^{4}$ Secondly, various morbidities associated with late-preterm birth may negatively impact on feeding, such as hyperbilirubinemia, hypoglycemia, respiratory difficulties, and dehydration. ${ }^{1,5,6}$ LPIs are more likely than term infants to be separated from their mothers for medical investigations and treatments. ${ }^{3,7}$ Avoiding separation, as in kangaroo mother care (KMC) has a positive impact on breastfeeding and breast milk production. ${ }^{8} \mathrm{KMC}$ may protect breastfeeding in this population, as lower rates of breastfeeding exclusivity and duration are found in LPIs as compared to term infants, ${ }^{9-12}$ thus KMC may allow them to better achieve the global standard of exclusive breastfeeding for the first six months of life. ${ }^{13}$

While research suggests that breastfeeding difficulties are important to consider in LPIs, literature is limited regarding specific breastfeeding characteristics of LPIs. ${ }^{14}$ 
Publications highlighting breastfeeding characteristics specific to LPIs, $, 7,15,16$ do not appear to be based on original research, but rather on clinical experience; or are now older than 10 years. In addition, limited research is available regarding LPIs breastfeeding in $\mathrm{KMC}$, an intervention known to promote breastfeeding. ${ }^{8}$

Increased knowledge of specific breastfeeding characteristics may be useful in early identification, and intervention for breastfeeding difficulties that may place LPIs at risk for the negative cyclic implications that poor breastfeeding has on milk intake, infant physiological status, maternal anxiety and milk supply. $7,10,14,17-20$ The aim of this study was to further investigate the breastfeeding characteristics of LPIs receiving $\mathrm{KMC}$.

\section{Materials and methods}

Institutional ethical clearance was obtained to conduct this descriptive, prospective, observational study. Prospective data collection took place for 12 weeks, from September to November 2016, in an established KMC unit in a South African academic hospital. In the unit, 20 mothers lodge in an open-dormitory, providing intermittent or continuous KMC to their infants. The KMC unit accepts healthy, lowbirth weight and premature infants, and full-term infants with feeding difficulties, from high care and the neonatal intensive care unit (NICU). Infants should typically have established oral feeding on admission into this unit, where the Baby Friendly Hospital Initiative $(\mathrm{BFHI})^{21}$ is implemented. Providing supplementary expressed, and occasionally donor, breast milk via cup at three-hourly feeding times in the unit ensures adequate milk intake. Direct breastfeeding is practiced in human immunodecifiency virus (HIV) exposed infants, as HIV positive mothers are on antiretroviral treatment during pregnancy and after birth, and their infants are placed on 
treatment from birth. If the mother's HIV viral load is high, pasteurization of expressed breast milk will take place.

Participant description

Non-probability, convenient sampling was used to select 73 LPIs (34 0/7 to 36 6/7) in a KMC unit. To provide a holistic view of LPIs in a KMC unit, infants with morbidities were not excluded. Participant and maternal characteristics have been represented in Table 4.

Table 4. Participant and maternal characteristics $(n=73)$

\begin{tabular}{|c|c|c|c|c|c|c|}
\hline & $\%$ & Mean & $\begin{array}{l}\text { Standard } \\
\text { deviation }\end{array}$ & Minimum & Maximum & Skewness \\
\hline \multicolumn{7}{|l|}{ Infant characteristics } \\
\hline Birth weight $(\mathrm{kg})^{*}$ & & 2.1 & 0.4 & 1.4 & 4.1 & 1.5 \\
\hline Current weight $(\mathrm{kg})$ & & 2.1 & 0.4 & 1.4 & 3.9 & 1.5 \\
\hline NICU stay duration (days) & & 6 & 7.6 & 0 & 41 & 3 \\
\hline KMC stay duration (days) & & 3.1 & 2.6 & 1 & 14 & 2.2 \\
\hline Chronological age (days) & & 9.5 & 9.1 & 2 & 55 & 2.9 \\
\hline Breastfeeding duration (days) & & 7.5 & 6.7 & 0 & 43 & 2.8 \\
\hline \multicolumn{7}{|l|}{ Maternal characteristics } \\
\hline Age (years) & & 29 & 7.2 & 16 & 43 & 0.1 \\
\hline At least secondary education* & 57.1 & & & & & \\
\hline Living in urban informal settlements ${ }^{\star *}$ & 64.4 & & & & & \\
\hline Previous breastfeeding experience & 64.4 & & & & & \\
\hline
\end{tabular}

Many participants presented with factors that could potentially influence breastfeeding, including being one of a twin (35.6\%), cesarean section delivery (61.6\%), HIV exposure (27.4\%), bronchopulmonary dysplasia (1.4\%), transient tachypnea of the newborn (19.2\%), patent ductus arteriosus not requiring surgery (13.7\%), respiratory distress syndrome (46.6\%), receiving oxygen via nasal cannula 
at the time of data collection (15.1\%), small for gestational age/intra-uterine growth restriction (31.5\%), hyperbilirubinemia (67.1\%), congenital disorders $(6.8 \%)$, including Down syndrome and hypospadias and craniofacial anomalies (6.8\%), including microcephaly, microtia and deformational plagiocephaly.

\section{Data collection}

Mothers provided voluntary informed consent (in English, Sepedi or isiZulu).

Background information was collected by medical file review and maternal interview. The Preterm Infant Breastfeeding Behavior Scale (PIBBS), ${ }^{16}$ was then completed following observation of one entire breastfeeding session. This validated tool, which the authors found had good inter-rater reliability (IRR), guides observations of preterm infants' breastfeeding. ${ }^{16}$ It sets out maturational steps for each breastfeeding characteristic, from immature, to mature term behaviors. ${ }^{16}$ The checklist was completed by speech-language therapists (SLT), not mothers, as intended by the authors of the PIBBS, as not all mothers were English-speaking.

Training in using the PIBBS took place between two SLTs, and 22 participants' breastfeeding sessions were jointly observed by both SLTs for IRR assessments. Cohen's Kappa values for five PIBBS items ranged from poor to very good, ${ }^{23}$ including latching-on (0.46, agreement: $76 \%)$, sucking (0.74, agreement: $85 \%)$, swallowing (0.37, agreement: $67 \%$ ), dull, glazed, open eyes (1.0, agreement: $100 \%)$, open eyes, active movements (1.0, agreement: $100 \%)$ and the letdown reflex $(-0.07$, agreement: 86\%). Given these varying values, joint review of all 22 participants' results with a third SLT, took place to reach a consensus. Reasons for discrepancies, such as differing levels of visibility of the throat and mouth by two 
raters, were discussed and criteria for observations of subsequent sessions by one rater were established.

Data analysis

Data were analyzed using IBM SPSS (Version 24). Cohen's Kappa Measure of Agreement was used to determine IRR. Descriptive statistics were calculated and statistically significant differences and associations were determined using the Fisher's exact test and chi-squared test procedures. The Spearman's correlation coefficient was determined for ordinal data. P-values of 0.05 were determined statistically significant.

\section{Results}

Of the 73 participants, $97.3 \%$ were on full oral feeds (cup-feeding and/or breastfeeding) at the time of data collection and had been for a mean of 7.2 days (SD: 7.2, positively skewed: 2.8$)$. Most participants (72.6\%) began breastfeeding on the day of birth, but only $13.7 \%$ were directly breastfeeding without supplementary cup-feeding or naso- or orogastric feeding. Up to $26 \%$ of participants required several days of naso- or orogastric feeding (M: 6.3, SD: 5.9 ) and $86.3 \%$ received cup-feeding of breast milk (M: 6.0 days, SD: 7.3) to supplement breastfeeding. Few mothers (5.5\%) had lactation difficulties at some point after giving birth. At the time of data collection, all mothers used their own expressed breast milk for supplementary cup-feeding or naso- or orogastric feeding, rather than donor milk or formula. 
Table 5. Breastfeeding characteristics according to chronological age-groups $(n=73)$

\begin{tabular}{|c|c|c|c|c|c|c|c|c|c|}
\hline \multirow[b]{2}{*}{$\begin{array}{l}\text { Breastfeeding } \\
\text { characteristics }\end{array}$} & \multirow{2}{*}{\multicolumn{2}{|c|}{ Descriptive }} & \multirow[b]{2}{*}{ Overall (\%) } & \multicolumn{3}{|c|}{ Chronological age (days) } & \multicolumn{3}{|c|}{ Significance } \\
\hline & & & & $1-7(\%)$ & $8-14(\%)$ & $15+(\%)$ & $\begin{array}{l}\text { Fisher's } \\
\text { exact }\end{array}$ & $\begin{array}{l}\text { Spearman's } \\
\text { correlation } \\
\text { coefficient }\end{array}$ & $p$-value \\
\hline Overall & & & $73(100.0)$ & $37(50.7)$ & $25(34.2)$ & $11(15.1)$ & & & \\
\hline \multicolumn{10}{|l|}{ Rooting } \\
\hline None & $\mathrm{N} / \mathrm{A}$ & & $26(35.6)$ & $13(35.1)$ & $11(44.0)$ & 2 (18.2) & 0.366 & 0.096 & 0.424 \\
\hline Some & & & $35(47.9)$ & 19 (51.4) & $11(44.0)$ & $5(45.4)$ & & & \\
\hline Obvious & & & $12(16.5)$ & $5(13.5)$ & $3(12.0)$ & $4(36.4)$ & & & \\
\hline \multicolumn{10}{|l|}{ Depth of latching } \\
\hline None & $\mathrm{N} / \mathrm{A}$ & & $2(2.8)$ & $1(2.7)$ & $1(4.0)$ & $0(0.0)$ & 0.517 & 0.215 & 0.065 \\
\hline Part nipple & & & $21(28.8)$ & $14(37.8)$ & $6(24.0)$ & $1(9.1)$ & & & \\
\hline Whole nipple & & & $45(61.6)$ & $20(54.1)$ & $16(64.0)$ & $9(81.8)$ & & & \\
\hline Some areola & & & $5(6.8)$ & $2(5.4)$ & $2(8.0)$ & $1(9.1)$ & & & \\
\hline \multicolumn{10}{|c|}{ Latching duration (min) } \\
\hline None & Mean* & 4.6 & $2(2.7)$ & $1(2.7)$ & $1(4.0)$ & $0(0.0)$ & 0.807 & 0.002 & 0.986 \\
\hline$<1 \min$ & $S D$ & 3.2 & 9 (12.3) & $6(16.2)$ & $2(8.0)$ & $1(9.1)$ & & & \\
\hline $1-5$ & Skewness & 1.5 & $45(61.6)$ & $20(54.1)$ & $18(72.0)$ & $7(63.6)$ & & & \\
\hline $6-10$ & Kurtosis & 2.6 & $14(19.2)$ & $7(18.9)$ & $4(16.0)$ & $3(27.3)$ & & & \\
\hline$\geq 11$ & & & $3(4.2)$ & $3(8.1)$ & $0(0.0)$ & $0(0.0)$ & & & \\
\hline \multicolumn{10}{|l|}{ Sucking } \\
\hline None & $\mathrm{N} / \mathrm{A}$ & & $2(2.7)$ & $1(2.7)$ & $1(4.0)$ & $0(0.0)$ & 0.553 & 0.108 & 0.127 \\
\hline Licking & & & $3(4.1)$ & $3(8.2)$ & $0(0.0)$ & $0(0.0)$ & & & \\
\hline Single sucks & & & $14(19.2)$ & 7 (18.9) & $6(24.0)$ & $1(9.1)$ & & & \\
\hline Short bursts & & & $20(27.4)$ & $12(32.4)$ & $4(16.0)$ & $4(36.4)$ & & & \\
\hline Long bursts & & & $34(46.6)$ & $14(37.8)$ & $14(56.0)$ & $6(54.5)$ & & & \\
\hline \multicolumn{10}{|c|}{ Longest sucking burst (number of sucks) ${ }^{\star *}$} \\
\hline $1-5$ & Mean & 18.8 & $10(14.7)$ & $6(18.1)$ & $3(12.5)$ & $1(9.1)$ & 0.445 & 0.129 & 0.288 \\
\hline $6-10$ & $S D$ & 10.5 & $12(17.6)$ & $5(15.2)$ & $5(20.8)$ & $2(18.2)$ & & & \\
\hline $11-15$ & Skewness & -0.2 & $8(11.8)$ & $5(15.2)$ & $2(8.3)$ & $1(9.1)$ & & & \\
\hline $16-20$ & Kurtosis & -1.6 & $5(7.4)$ & $2(6.1)$ & $1(4.2)$ & $2(18.2)$ & & & \\
\hline $21-25$ & & & $5(7.4)$ & $5(15.2)$ & $0(0.0)$ & $0(0.0)$ & & & \\
\hline$\geq 26$ & & & $28(41.1)$ & $10(30.2)$ & $13(54.2)$ & $5(45.4)$ & & & \\
\hline \multicolumn{10}{|l|}{ Swallowing } \\
\hline None & $\mathrm{N} / \mathrm{A}$ & & $9(12.3)$ & $6(16.3)$ & $3(12.0)$ & $0(0.0)$ & 0.369 & 0.216 & 0.071 \\
\hline Occasional & & & $25(34.3)$ & $14(37.8)$ & $9(36.0)$ & $2(18.2)$ & & & \\
\hline Repeated & & & $39(53.4)$ & $17(45.9)$ & $13(52.0)$ & $9(81.8)$ & & & \\
\hline \multicolumn{10}{|c|}{ Length of time baby was held for breastfeeding (min) } \\
\hline $1-5$ & Mean & 17.8 & $29(39.7)$ & $17(45.9)$ & $9(36.0)$ & $3(27.3)$ & 0.474 & 0.112 & 0.353 \\
\hline $6-10$ & $S D$ & 4.6 & $27(37.0)$ & $11(29.7)$ & $12(48.0)$ & $4(36.3)$ & & & \\
\hline $11-15$ & Skewness & 1.0 & $13(17.8)$ & $7(18.9)$ & $3(12.0)$ & $3(27.3)$ & & & \\
\hline $16-20$ & Kurtosis & 0.9 & $3(4.1)$ & $2(5.5)$ & $1(4.0)$ & $0(0.0)$ & & & \\
\hline$\geq 21$ & & & $1(1.4)$ & $0(0.0)$ & $0(0.0)$ & $1(9.1)$ & & & \\
\hline
\end{tabular}

Table 5 indicates the breastfeeding characteristics exhibited by participants as a group, and when divided into three chronological age-groups. Breastfeeding characteristics are based on test items of the PIBBS. For the sake of clarity, in the 
present study, the test item 'how much of the breast was inside the baby's mouth' is referred to as depth of latching, and 'latching-on and staying fixed to the breast' is referred to as latching duration. According to the PIBBS, ${ }^{16}$ mature behaviors are obvious rooting, latching onto the nipple and some areola, latching-on for long durations, long sucking bursts and repeated swallowing. ${ }^{16}$ Based on this classification, no participant exhibited the most mature behavior for every breastfeeding characteristic. Less than $50 \%$ of participants exhibited the most mature behavior for each breastfeeding characteristic according to the PIBBS, with the exception of repeated swallowing (53.3\%). Most participants did not exhibit obvious rooting (83.5\%). Most participants latched-on (97.3\%), but those who did, latched shallowly (93\%) and for less than five minutes (76.1\%). Approximately half the participants exhibited long sucking bursts (46.6\%), with a mean longest burst of 18.8 sucks, with considerable variation (SD: 10.5). Approximately half the participants exhibited repeated swallowing (53.4\%), the other half swallowing occasionally (34.3\%) or not at all (12.3\%). Participants were held for breastfeeding for a mean of 17.8 minutes (SD: 4.6 , positive skewness: 1.0$)$ but most were held for under 10 minutes $(76.7 \%)$.

No statistically significant relationships between chronological age and breastfeeding characteristics were found. However, a trend towards a higher percentage of older participants exhibiting mature behaviors could be seen for most breastfeeding characteristics, including rooting, depth of latching, sucking and swallowing. Results of latching duration, longest sucking burst and length of time held for breastfeeding did not show clear trends. 
Table 6 shows similar results. Participants that exhibited the most mature behaviors according to the PIBBS classification, had on average, been breastfeeding for longer than those exhibiting less mature behaviors, except for latching duration. Infants with more experience breastfeeding tended to breastfeed for shorter durations.

Table 6. Breastfeeding characteristics in relation to mean number of days breastfeeding $(n=73)$

\begin{tabular}{|c|c|c|}
\hline Breastfeeding characteristic & $\begin{array}{l}\text { Frequency } \\
(\%)\end{array}$ & $\begin{array}{l}\text { Mean no. days } \\
\text { breastfeeding (SD) }\end{array}$ \\
\hline \multicolumn{3}{|l|}{ Rooting } \\
\hline Not obvious/none & $61(83.6)$ & $6.9(5.3)$ \\
\hline Obvious & $12(16.4)$ & $10.3(11.3)$ \\
\hline \multicolumn{3}{|l|}{ Depth of latching } \\
\hline Whole nipple/less & $68(93.2)$ & $7.4(6.7)$ \\
\hline Some areola & $5(6.8)$ & $8.0(6.1)$ \\
\hline \multicolumn{3}{|l|}{ Latching duration (min) } \\
\hline$<15$ & $71(97.3)$ & $7.6(6.7)$ \\
\hline$\geq 15$ & $2(2.7)$ & $4.0(0.0)$ \\
\hline \multicolumn{3}{|l|}{ Sucking } \\
\hline Short bursts/less & $39(53.4)$ & $6.7(5.6)$ \\
\hline Long bursts & $34(46.6)$ & $8.3(7.7)$ \\
\hline \multicolumn{3}{|c|}{ Longest sucking burst (number of sucks) } \\
\hline$<30$ & $48(65.6)$ & $6.8(5.2)$ \\
\hline$\geq 30$ & $25(34.4)$ & $8.8(8.7)$ \\
\hline \multicolumn{3}{|l|}{ Swallowing } \\
\hline Occasional/none & $34(46.6)$ & $5.8(4.7)$ \\
\hline Repeated & $39(53.4)$ & $9.0(7.7)$ \\
\hline \multicolumn{3}{|c|}{ Length of time baby was held for breastfeeding (min) } \\
\hline$<15$ & $67(91.8)$ & $7.6(6.9)$ \\
\hline$\geq 15$ & $6(8.2)$ & $6.3(2.7)$ \\
\hline
\end{tabular}

Table 7 indicates the differences in breastfeeding characteristics between participants with and without RDS. No statistically significant differences were detected. However, a larger percentage of participants without RDS tended to exhibit the most mature behaviors according to the PIBBS classification, than the percentage of participants with RDS, except for latching duration. A larger percentage of participants with RDS tended to breastfeed for longer durations, than the percentage of participants without RDS. 


\begin{tabular}{|c|c|c|c|}
\hline \multirow[b]{2}{*}{ Breastfeeding characteristic } & \multicolumn{3}{|c|}{ Diagnosis of RDS } \\
\hline & Overall (\%) & $\begin{array}{l}\text { Absent } \\
\text { (\%) }\end{array}$ & $\begin{array}{l}\text { Present } \\
\text { (\%) }\end{array}$ \\
\hline Overall (\%) & $73(100.0)$ & 39 (53.4.) & $34(46.6)$ \\
\hline \multicolumn{4}{|l|}{ Rooting } \\
\hline Not obvious/none & $61(83.6)$ & $31(79.5)$ & $30(88.2)$ \\
\hline Obvious & $12(16.4)$ & $8(20.5)$ & $4(11.8)$ \\
\hline \multicolumn{4}{|l|}{ Depth of latching } \\
\hline Whole nipple/less & $68(93.2)$ & $36(92.3)$ & $32(94.1)$ \\
\hline Some areola & $5(6.8)$ & $3(7.7)$ & $2(5.9)$ \\
\hline \multicolumn{4}{|l|}{ Latching duration (min) } \\
\hline$<15$ & $71(97.3)$ & $34(97.1)$ & $26(96.3)$ \\
\hline$\geq 15$ & $2(2.7)$ & $1(2.9)$ & $1(3.7)$ \\
\hline \multicolumn{4}{|l|}{ Sucking } \\
\hline Short bursts/less & $39(53.4)$ & $19(48.7)$ & $20(58.8)$ \\
\hline Long bursts & $34(46.6)$ & $20(51.3)$ & $14(41.2)$ \\
\hline \multicolumn{4}{|c|}{ Longest sucking burst (number of sucks) } \\
\hline$<30$ & $43(63.2)$ & $21(55.3)$ & $22(73.3)$ \\
\hline$\geq 30$ & $25(36.8)$ & $17(44.7)$ & $8(26.7)$ \\
\hline \multicolumn{4}{|l|}{ Swallowing } \\
\hline Occasional/none & $34(46.6)$ & $15(38.5)$ & $19(55.9)$ \\
\hline Repeated & $39(53.4)$ & $24(61.5)$ & $15(44.1)$ \\
\hline \multicolumn{4}{|c|}{ Length of time baby was held for breastfeeding (min) } \\
\hline$<15$ & 67 (91.8) & 37 (94.9) & 30 (88.2) \\
\hline$\geq 15$ & $6(8.2)$ & $2(5.1)$ & $4(11.8)$ \\
\hline
\end{tabular}

The letdown reflex was perceived in $98.6 \%$ of mothers and no breast problems were reported. The participants' general behavior varied, with many infants exhibiting several behaviors during one breastfeeding session (Table 8).

Table 8. General behavior during breastfeeding

\begin{tabular}{ll} 
General behaviour & Frequency $(\%)^{*}$ \\
\hline Closed eyes, no movements & $58(79.5)$ \\
Cried, fussed audibly & $21(28.8)$ \\
Open eyes, dull/glazed look & $15(20.5)$ \\
Closed eyes, active movements & $14(19.2)$ \\
Drowsy, open eyes, heavy-lidded & $13(17.8)$ \\
Eyes wide open, achieved eye contact & $4(5.5)$ \\
Open eyes, active movements & $4(5.5)$ \\
Eyes wide open, looked tense/afraid & $1(1.4)$ \\
\hline${ }^{*}$ Total \% > 100 as participants exhibited >1 behavior
\end{tabular}


The influence of environment on breastfeeding characteristics is depicted in Table 9. When the environment was quiet and private, rather than disturbing, more infants exhibited the most mature behavior for each breastfeeding characteristic, except for depth of latching. Participants breastfeeding when the environment was quiet tended to be held for breastfeeding for longer.

Table 9. Breastfeeding characteristics in relation to the environment $(n=73)$

\begin{tabular}{|c|c|c|c|}
\hline \multirow[b]{2}{*}{ Breastfeeding characteristic } & \multirow[b]{2}{*}{$\begin{array}{l}\text { Overall } \\
(\%)\end{array}$} & \multicolumn{2}{|c|}{$\begin{array}{l}\text { Influence of the } \\
\text { environment }\end{array}$} \\
\hline & & $\begin{array}{l}\text { Some } \\
\text { disturbance } \\
\text { (\%) }\end{array}$ & $\begin{array}{l}\text { Quiet/private } \\
(\%)\end{array}$ \\
\hline Overall (\%) & $73(100.0)$ & $33(45.2)$ & $40(54.8)$ \\
\hline \multicolumn{4}{|l|}{ Rooting } \\
\hline Not obvious/none & $61(83.6)$ & $31(93.9)$ & $30(75.0)$ \\
\hline Obvious & $12(16.4)$ & $2(6.1)$ & $10(25.0)$ \\
\hline \multicolumn{4}{|l|}{ Depth of latching } \\
\hline Whole nipple/less & $68(93.2)$ & $28(84.8)$ & $40(100.0)$ \\
\hline Some areola & $5(6.8)$ & $5(15.2)$ & $0(0.0)$ \\
\hline \multicolumn{4}{|l|}{ Latching duration (min) } \\
\hline$<15$ & $71(97.3)$ & $33(100.0)$ & $38(95.0)$ \\
\hline$\geq 15$ & $2(2.7)$ & $0(0.0)$ & $2(5.0)$ \\
\hline \multicolumn{4}{|l|}{ Sucking } \\
\hline Short bursts/less & $39(53.4)$ & $18(54.5)$ & $21(52.5)$ \\
\hline Long bursts & $34(46.6)$ & $15(45.5)$ & $19(47.5)$ \\
\hline \multicolumn{4}{|c|}{ Longest sucking burst (number of sucks) } \\
\hline$<30$ & $48(65.6)$ & $24(72.7)$ & $24(60.0)$ \\
\hline$\geq 30$ & $25(34.4)$ & $9(27.3)$ & $16(40.0)$ \\
\hline \multicolumn{4}{|l|}{ Swallowing } \\
\hline Occasional/none & $34(46.6)$ & $18(54.5)$ & $16(40.0)$ \\
\hline Repeated & $39(53.4)$ & $15(45.5)$ & $24(60.0)$ \\
\hline \multicolumn{4}{|c|}{ Length of time baby was held for breastfeeding ( $\min )$} \\
\hline$<15$ & $67(91.8)$ & $33(100.0)$ & $34(85.0)$ \\
\hline$\geq 15$ & $6(8.2)$ & $0(0.0)$ & $6(15.0)$ \\
\hline
\end{tabular}

\section{Discussion}

Results highlight specific breastfeeding characteristics and difficulties in this sample of 73 LPIs receiving KMC. Most participants were not exhibiting obvious rooting $(83.5 \%)$, which was unexpected, as this reflex is expected from 28 weeks $G A{ }^{24}$ However, rooting can be influenced by reduced alertness, ${ }^{25}$ which may have been 
the case in this study, as the predominant behavior while breastfeeding was closed eyes without movements $(79.5 \%)$. For breastfeeding, rooting is important, as it gives an indication of feeding readiness and may impact on successful latching. ${ }^{25,26}$ Latching was indeed affected in this sample. Although most latched-on (97.3\%), latching was shallow, only onto the nipple or less, in $93 \%$ of participants who latched-on. Poor latching, often highlighted in LPIs, ${ }^{5,14,27}$ is concerning, as this may impact on the efficiency of milk transfer. ${ }^{25}$

Immaturity in sucking and swallowing were also expected, given previous research indicating that neurological immaturity in LPIs may impact on these characteristics, and that coordinating these with breathing, only matures and is refined in the third trimester. 5,14,27,28 The suck-swallow-breathe ratio for efficient breastfeeding in term infants is $1-1-1$, to $3-1-1 .^{24}$ Less frequent swallowing may indicate poor milk transfer. ${ }^{24}$ While repeated swallowing was observed in approximately half the participants (53.4\%), 46.6\% were not swallowing or swallowing only occasionally, and may thus not have achieved adequate milk transfer.

The majority (67.8\%) of participants' longest sucking bursts were within the norms for term infants. ${ }^{24}$ However, this mean value reflects the longest sucking burst. The average sucking burst length throughout the breastfeeding session may have been shorter, as $53.4 \%$ of participants exhibited short sucking bursts or less.

Nevertheless, Nyqvist ${ }^{29}$ states that even with short sucking bursts, preterm infants can be successful breast-feeders if milk transfer is efficient. However, results of this study suggest participants as a group may have had inefficient milk transfer, given the number of participants with shallow latching and infrequent swallowing. Infrequent swallowing may be observed if an infant is exhibiting non-nutritive 
sucking, rather than nutritive sucking. ${ }^{26}$ Non-nutritive sucking creates slower milk transfer with the risk of insufficient intake if the breastfeeding session is short. ${ }^{25}$

Although the mean length of time held for breastfeeding was 17.8 minutes (Positive skewness: 1.0), most participants were held for breastfeeding for under 10 minutes (76.7\%). Typically, breastfeeding session length is not an accurate indicator of successful breastfeeding, as this may vary considerably depending on the infant. ${ }^{25} \mathrm{~A}$ short breastfeeding session may indicate an efficient breast-feeder, able to achieve sufficient milk intake in a short period. ${ }^{25}$ The results suggest that participants, as a group, were not efficient breast-feeders and the shorter time held for breastfeeding may be an indication of poor endurance, a difficulty frequently highlighted in LPIs..$^{5,7,19}$ One explanation for poor endurance, may be the high rate of respiratory difficulties in this sample ${ }^{26}(15 \%$ required oxygen at the time of evaluation and almost $50 \%$ had RDS). However, results indicated that more infants with RDS had breastfeeding sessions longer than 15 minutes, than infants without RDS. This longer breastfeeding session duration, may be due to these infants requiring longer rest periods, and periods of catch-up breathing within the session. Length of time held for breastfeeding may also have been influenced by the mothers being aware that they would be top-up cup-feeding at a later stage. This may have contributed to shorter breastfeeding sessions, to allow time for cup-feeding. Additionally, Nyqvist ${ }^{29}$ states that regular top-up cup-feeding may decrease milk intake at the breast, also potentially contributing to shorter breastfeeding sessions.

It was surprising that less than $55 \%$ of participants exhibited the most mature behavior for each breastfeeding characteristic, according to the PIBBS. Nyqvist et al. ${ }^{16}$ found that 60 to $64 \%$ of LPIs exhibited the most mature behavior for each 
characteristic. Fewer breastfeeding difficulties were expected in this study, given the known positive-influence of $\mathrm{KMC}$ on breastfeeding. ${ }^{8}$ Nyqvist et al. ${ }^{16}$ did not specify whether infants with morbidities were included in their sample, which may explain these differing results. In this sample, many participants presented with medical risk factors which previous research has associated with feeding difficulties, such as RDS. ${ }^{19,30-33}$ For example, the results of the present study appear to support that RDS may impact on breastfeeding. Although these results should be interpreted with caution due to a lack of statistical significance, Table 4 indicates that a larger percentage of participants without RDS exhibited mature breastfeeding characteristics, than the percentage of participants with RDS, except for latching duration. Infants in the KMC unit are typically admitted for weight gain and feeding difficulties. These infants may have higher percentages of morbidity, with a resultant higher percentage of infants with feeding difficulties than would be typical of healthy LPIs immediately discharged. However, LPIs in general are more likely to present with many of these medical risk factors than term infants, ${ }^{2,33}$ making it important that LPIs with these conditions not be overlooked..

Although results did not indicate statistical significance, there appeared to be a trend towards older participants exhibiting more mature breastfeeding characteristics. Additionally, all breastfeeding characteristics were more mature in infants breastfeeding for more days, with the exception of latching duration. The results of latching duration may have been influenced by the fact that only two participants latched-on longer than 15 minutes. Participants with more experience directly breastfeeding tended to breastfeed for shorter sessions, which may be an indication of better breastfeeding efficiency. Although these results should be interpreted with 
caution given the lack of statistical significance, the trends tentatively suggest that with time and experience (infant and maternal), the maturity of breastfeeding may improve. This is a concept supported by literature. ${ }^{34,35}$

The most frequent behavior exhibited by participants, was closed eyes and no movements, which may indicate sleepy or drowsy behavior, a predominant state in preterm infants. ${ }^{26}$ This behavior is ambiguous, as deep sleep, or drowsiness, may hinder or promote breastfeeding respectively. ${ }^{25}$ However, the second most frequently observed behavior, crying and fussing, would clearly hinder successful breastfeeding. ${ }^{25}$ Few participants presented with alert behaviors, which would promote successful direct breastfeeding. ${ }^{25,26}$

Results of this study suggest that a quiet, private environment fosters more mature direct breastfeeding characteristics, given that more participants exhibited mature behaviors for all breastfeeding characteristics, except for depth of latching, when the environment was quiet. Participants breastfeeding when the environment was quiet tended to breastfeed for longer, which may reflect the lack of disturbance in the environment. This is in line with literature that states that successful oral feeding requires adequate behavioral state organization, ${ }^{26}$ and preterm infants are easily overstimulated by environmental disturbance. ${ }^{36}$ The open-dormitory set-up may thus interfere with preterm infants who may have difficulty with state-regulation. Although these results provide preliminary information regarding the possible impact of the environment on breastfeeding characteristics, observation of multiple breastfeeding sessions to further investigate this concept, would be valuable. This would allow for a better understanding of the extent to which environment impacts on breastfeeding 
success, and to what extent other factors, such as an infant's individual temperament, may impact on breastfeeding.

Although lactation difficulties in mothers of LPIs may impact on the success of breastfeeding, ${ }^{19}$ few had lactation difficulties in this study, possibly associated with the positive influence of $\mathrm{KMC}$ and regular expressing of breast milk. ${ }^{37}$ The letdown reflex was perceived in almost all mothers (98.6\%) and no breast problems were reported. Thus, maternal factors appear not to have impacted significantly on the participants' breastfeeding.

The breastfeeding characteristics indicate subtle difficulties, which may have placed this sample of LPIs at risk for decreased milk transfer and intake by direct breastfeeding alone. A previous study found $33 \%$ of LPIs required some form of nutritional support, in addition to breastfeeding. ${ }^{38}$ The higher percentage of infants requiring supplementary naso- or orogastric-feeding (26\%) and cup-feeding (86.3\%) in the current study may be due to top-up cup-feeding being common in the KMC unit to ensure adequate milk intake. While this volume-driven supplementation may have increased the percentage of participants receiving cup-feeding, it nevertheless indicates a concern that direct breastfeeding alone would be insufficient. This need for supplementation in LPIs has been discussed in literature,,$^{7,20,38}$ and cup-feeding specifically has been highlighted as an effective transition to direct breastfeeding in LPIs. ${ }^{39}$ However, Nyqvist ${ }^{29}$ states that for preterm infants, more frequent cue-based direct breastfeeding sessions may promote greater milk intake at the breast than regular scheduled direct breastfeeding with top-up cup-feeding. The author adds that cup-feeding should only be occasional. 
SLTs and other healthcare professionals working with LPIs should be vigilant for subtle breastfeeding difficulties, which may typically be overlooked. Increased knowledge regarding breastfeeding characteristics may allow for more specific and individualized support for this population, such as prioritizing a quiet environment and allowing infants to 'practice' suckling at the nipple, even if direct breastfeeding is not yet established. Interventions such as cue-based breastfeeding sessions with occasional cup-feeding to supplement breastfeeding should be considered and further investigated. ${ }^{29,39}$ Such interventions should be employed in order to bestsupport these vulnerable LPIs, who may be at risk for cognitive and behavioral difficulties well-beyond infancy. ${ }^{40}$

A number of study limitations should be mentioned. Firstly, the GA of participants was based on the New Ballard Score, which is not as reliable as ultrasounds for determining GA. ${ }^{22}$ Although observation is considered the least-invasive method of assessing breastfeeding, ${ }^{16}$ the presence of an observer may nevertheless impact on maternal and infant behavior. Observations may also be subjective, as indicated by IRR results. An isolated breastfeeding session was observed, which may not give an indication of the average breastfeeding performance of participants. Due to the admission criteria in the KMC unit, it was not possible to observe infants on a specific, constant day after birth. Keeping the day of observation constant, and thus chronological age and breastfeeding experience constant, may have allowed further investigation into differences in breastfeeding characteristics between infants of 34 weeks $\mathrm{GA}$, as opposed to those of 35 or 36 weeks $\mathrm{GA}$.

A similar study, with a larger sample would allow for more in-depth analysis of factors impacting on breastfeeding characteristics in LPIs, such as RDS and other 
medical factors. Further investigation into the efficiency of milk transfer in LPIs by test-weighing, as well as investigating whether nutritive or non-nutritive sucking is their predominant sucking characteristic, should take place. In addition, determining the impact of a mother's previous breastfeeding experience on breastfeeding characteristics would be valuable. Including immediately-discharged, healthy LPIs in a future study may be valuable for better generalization and evaluation of the impact of $\mathrm{KMC}$ on breastfeeding characteristics. Term and very premature infants can also be included to compare the level of maturity of breastfeeding characteristics. To date, no original research could be found regarding breastfeeding characteristics of LPIs receiving KMC. While results of this study highlight further investigation is still required, this study may provide exploratory information, which may serve as a basis for further research in this field.

\section{Conclusion}

In this sample of LPIs in a KMC unit, participants exhibited specific breastfeeding characteristics and difficulties. This knowledge may allow for more individualized feeding support for this vulnerable and often-overlooked population, potentially preventing negative cyclical implications of poor breastfeeding, and unrealistic expectations of those working with LPIs. Further research is still required to examine the effect of KMC on breastfeeding in LPIs.

\section{Acknowledgements}

Thanks go to the Pediatric Department of Kalafong Hospital, the healthcare staff, all participants' mothers and Dr Dion van Zyl, statistician, for making this study possible.

\section{References}


1. Kuzniewicz MW, Parker SJ, Schnake-Mahl A, Escobar GJ. Hospital readmissions and emergency department visits in moderate preterm, late preterm, and early term infants. Clin Perinatol. 2013;40:753-775.

2. Wang ML, Dorer DJ, Fleming MP, Catlin EA. Clinical outcomes of near-term infants. Pediatrics. 2004;114(2):372-37.

3. The Academy of Breastfeeding Medicine. ABM clinical protocol number 10: Breastfeeding the late preterm infant (34 0/7 to 36 6/7 weeks gestation). Breastfeed Med. 2011;6(3):151-156.

4. Shapiro-Mendoza CK, Lackritz EM. Epidemiology of late and moderate preterm birth. Semin Fetal Neonatal Med. 2012;17:120-125.

5. Cleaveland K. Feeding challenges in the late preterm infant. Neonatal Netw. 2010;29(1):37-41.

6. Gouyon JB, lacobelli S, Ferdynus C, Bonsante F. Neonatal problems of late and moderate preterm infants. Semin Fetal Neonatal Med. 2012;17:146-152.

7. Radtke J V. The paradox of breastfeeding-associated morbidity among late preterm infants. J Obstet Gynecol Neonatal Nurs. 2012;40(1):1-21.

8. Moore E, Anderson GC, Bergman N. Early skin-to-skin contact for mothers and their healthy newborn infants. Cochrane Database Syst Rev. 2012;5(3):1-75.

9. Goyal NK, Attanasio LB, Kozhimannil KB. Hospital care and early breastfeeding outcomes among late preterm, early-term, and term infants. Birth. 2014;41(4):330-338. 
10. McDonald SW, Benzies KM, Gallant JE, McNeil D, Dolan SM, Tough SC. A comparison between late preterm and term infants on breastfeeding and maternal mental health. Matern Child Heal. 2013;17:1468-1477.

11. Zanardo V, Gambina I, Begley C, et al. Psychological distress and early lactation performance in mothers of late preterm infants. Early Hum Dev. $2011 ; 87(4): 321-323$.

12. Hackman NM, Alligood-Percoco N, Martin A, Zhu J, Kjerulff KH. Reduced breastfeeding rates in firstborn late preterm and early term infants. Breastfeed Med. $2016 ; 11(3): 119-125$.

13. World Health Organization [WHO]. Global Strategy for Infant and Young Child Feeding. Geneva: WHO; 2003.

14. Eidelman Al. The challenge of breastfeeding the late preterm and the earlyterm infant. Breastfeed Med. 2016;11(3):99.

15. Horgan MJ. Management of the late preterm infant: Not quite ready for prime time. Pediatr Clin North Am. 2015;62:439-451.

16. Nyqvist KH, Rubertsson C, Ewald U, Sjödén PO. Development of the preterm infant breastfeeding behavior scale (PIBBS): A study of nurse-mother agreement. $J$ Hum Lact. 1996;12(3):207-219.

17. Demirci JR, Happ MB, Bogen DL, Albrecht SA, Cohen SM. Weighing worth against uncertain work: The interplay of exhaustion, ambiguity, hope and disappointment in mothers breastfeeding late preterm infants. Matern Child Nutr. 2015;11:59-72. 
18. Lau C, Hurst NM, Smith EO, Schanler RJ. Ethnic/racial diversity, maternal stress, lactation and very low birthweight infants. J Perinatol. 2007;27:399-408.

19. Meier PP, Furman LM, Degenhardt M. Increased lactation risk for late preterm infants and mothers: Evidence and management strategies to protect breastfeeding. J Midwifery Women's Heal. 2007;52(6):579-587.

20. Meier P, Patel A, Wright K, Engstrom J. Management of breastfeeding during and after the maternity hospitalization for late preterm infants. Clin Perinatol. 2013;40(4):689-705.

21. World Health Organization [WHO]. Baby-Friendly Hospital Initiative.; 2009. http://www.who.int/nutrition/publications/infantfeeding/bfhi.

22. Ballard JL, Khoury JC, Wedig K, Wang L, Eilers-Welsman BL, Lipp R. New Ballard Score, expanded to include extremely premature infants. J Pediatr. $1991 ; 119(3): 417-423$

23. Fleiss J, Levin B, Paik MC. Statistical Methods for Rates and Proportions. 3rd Editio. John Wiley \& Sons, Inc.; 2003.

24. Genna CW, Sandora L. Breastfeeding: Normal sucking and swallowing. In: Genna CW, ed. Supporting Sucking Skills in Breastfeeding Infants. 2nd Editio. Burlington: Jones \& Bartlett Learning; 2013:1-48.

25. Cadwell K. Latching-on and suckling of the healthy term neonate: Breastfeeding assessment. J Midwifery Women's Heal. 2007;52(6):638-642.

26. Wolf L, Glass RP. Feeding and Swallowing Disorders in Infancy: Assessment and Management. Tucson: Therapy Skill Builders; 1992. 
27. Medoff Cooper B, Holditch-Davis D, Verklan MT, et al. Newborn clinical outcomes of the AWHONN late preterm infant research-based practice project. $J$ Obstet Gynecol Neonatal Nurs. 2012;41:774-785. doi:10.1111/j.15526909.2012.01401.

28. Giannì ML, Bezze $\mathrm{E}$, Sannino $\mathrm{P}$, et al. Facilitators and barriers of breastfeeding late preterm infants according to mothers' experiences. BMC Pediatr. 2016;16(179):1-8.

29. Nyqvist KH. Lack of knowledge persists about early breastfeeding competence in preterm infants. J Hum Lact. 2013;29(3):296-299.

30. Van Nostrand SM, Bennett LN, Coraglio VJ, Guo R, Muraskas JK. Factors influencing independent oral feeding in preterm infants. J Neonatal Perinatal Med. 2015;8:15-21.

31. Giannì ML, Sannino $P$, Bezze $E$, et al. Effect of co-morbidities on the development of oral feeding ability in pre-term infants: A retrospective study. Sci Rep. 2015;5:1-8.

32. Jadcherla SR, Wang M, Vijayapal AS, Leuthner SR. Impact of prematurity and co-morbidities on feeding milestones in neonates: A retrospective study. $J$ Perinatol. 2010;30(3):201-208.

33. Natile M, Ventura ML, Colombo M, et al. Short-term respiratory outcomes in late preterm infants. Ital J Pediatr. 2014;40:52-62.

34. White-Traut R, Pham T, Rankin K, Norr K, Shapiro N, Yoder J. Exploring factors related to oral feeding progression in premature infants. Adv Neonatal Care. 
2013;13(4):288-294.

35. Nyqvist $\mathrm{KH}$. Early attainment of breastfeeding competence in very preterm infants. Acta Paediatr. 2008;97:776-781.

36. Nyqvist KH. Breastfeeding preterm infants. In: Genna CW, ed. Supporting Sucking Skills in Breastfeeding Infants. 2nd Editio. Burlington: Jones \& Bartlett Learning; 2013:171-196.

37. Briere CE, Lucas R, McGrath JM, Lussier M, Brownell E. Establishing breastfeeding with the late preterm infant in the NICU. J Obstet Gynecol Neonatal Nurs. 2015;44:102-113.

38. Lapillonne A, O'Connor DL, Wang D, Rigo J. Nutritional recommendations for the late-preterm infant and the preterm infant after hospital discharge. $J$ Pediatr. 2013;162:S90-S100.

39. Yilmaz G, Caylan N, Karacan CD, Bodur I, Gokcay G. Effect of cup feeding and bottle feeding on breastfeeding in late preterm infants: A randomized controlled study. J Hum Lact. 2014;30(54):174-179.

40. Brumbaugh JE, Conrad AL, Lee JK, et al. Altered brain function, structure, and developmental trajectory in children born late preterm. Pediatr Res. 2016;80(2):197-203. 


\section{Chapter 4}

\section{Implications and conclusions}

\subsection{Chapter aim and outline}

The purpose of this chapter is to further elaborate on the results of this study, as word- and citation limits of the selected journal restricted the depth of discussion and description of the implications of the results in the article submitted. The discussion begins by elaborating on both the research implications and clinical implications of the results, later highlighting study limitations and future research directions. The chapter ends with a few concluding statements, in order to summarise the results of the study.

\subsection{Implications}

4.2.1. Breastfeeding rates. In the present study, only $13.7 \%$ of participants were directly breastfeeding without supplementary cup-feeding or tube-feeding at the time of data collection. This finding is similar to the results of another study, which found that only $21 \%$ of LPIs were directly breastfeeding on discharge, without supplementary feeds (Zanardo et al., 2011). Additionally, in the present study, only $72.4 \%$ of LPIs directly breastfed within the first 24 hours after birth. A similar result was found by McDonald et al. (2013), who found that $78.7 \%$ of LPIs directly breastfed within the first 24 hours after birth. The similarity between the results of the present study and these two previous studies, strengthens existing evidence of breastfeeding research in LPIs and adds to the knowledge-base regarding this population.

\subsubsection{Specific breastfeeding characteristics. This sample of LPIs exhibited} specific breastfeeding characteristics which could promote both successful breastfeeding, as well as breastfeeding characteristics which could contribute to subtle breastfeeding difficulties. Positive breastfeeding characteristics included that almost all participants were latching-on. Participants exhibited a mean longest 
sucking burst length within the norm for term infants (Genna \& Sandora, 2013), also a positive characteristic if the sucking exhibited was nutritive (Cadwell, 2007). Approximately half the participants exhibited repeated swallowing, which would promote efficient milk-transfer (Wolf \& Glass, 1992). Another positive breastfeeding characteristic was that there appeared to be a trend towards more successful breastfeeding in infants who were older and had more experience breastfeeding, suggesting that practice may facilitate more successful breastfeeding.

Breastfeeding characteristics which may have contributed to subtle difficulties included that although most participants were latching, they were exhibiting shallow latching, which may contribute to inefficient milk transfer (Wolf \& Glass, 1992). Additionally, although approximately half the participants were swallowing repeatedly, half were not swallowing or swallowing only occasionally, potentially contributing to reduced milk intake in approximately half the participants (Wolf \& Glass, 1992). Crying and fussing was the second most common behaviour, also potentially negatively impacting on breastfeeding (Cadwell, 2007). Additionally, these participants exhibited poorer breastfeeding characteristics when the environment was disturbing, indicating sensitivity to environmental disturbance.

Several breastfeeding characteristics may facilitate successful or poor breastfeeding, depending on the individual infant. Participants tended to be held for breastfeeding for short durations. While short breastfeeding session duration may indicate these participants were efficient feeders (Cadwell, 2007), it may also be an indication of poor endurance, a documented difficulty in LPIs (Radtke, 2012). The breastfeeding behaviour of closed eyes and no body movements may indicate that most participants were drowsy, a behaviour that may facilitate successful breastfeeding according to Wolf and Glass (1992). However, the behaviour of closed eyes and no movements may also be an indication of an infant sleeping deeply, which would not facilitate successful breastfeeding (Cadwell, 2007). Several authors state that alert, rather than drowsy or sleepy behaviours facilitate successful direct breastfeeding (Lefton-Greif \& Arvedson, 2016; Wolf \& Glass, 1992). These characteristics, taken holistically, do not point to severe breastfeeding difficulties, but rather more subtle breastfeeding difficulties and inefficiencies. 
Heightened awareness that LPIs breastfeeding characteristics may not contribute to severe difficulties but rather more subtle difficulties, may potentially prevent LPIs from being overlooked. The risk for overlooking these more subtle difficulties may be especially true in a KMC unit, where LPIs' breastfeeding skills may appear efficient when compared to the skills of more premature infants in the unit. Increased knowledge and vigilance for the identification of these potential difficulties may contribute to the earlier identification thereof, and resultant earlier- and more individualised treatment. This knowledge is particularly important for SLTs working in the KMC unit, as it is their role to identify breastfeeding difficulties, as well as develop and implement appropriate treatment and feeding plans for each infant (American Speech-Language-Hearing Association [ASHA], 2017). This should be done in collaboration with neonatologists, nursing staff, doctors, dieticians and parents (ASHA, 2017).

Knowledge of the subtle difficulties may prevent mothers, SLTs and other healthcare professionals from having unrealistic expectations of these vulnerable LPIs, who might be expected to perform on par with term infants. The results of a study by Nyqvist et al. (1996) indicated that the breastfeeding characteristics of LPIs were not as mature as term infants. During the original development of the PIBBS by Nyqvist et al. (1996), the authors of the PIBBS found that the percentage of LPIs exhibiting mature behaviours on the PIBBS, was between $59.8 \%$ and $64.0 \%$, higher than in this study (less than 55\% for each breastfeeding characteristic). Nyqvist et al. (1996) indicated that the percentage of LPIs achieving mature behaviours for each breastfeeding characteristic were as follows: obvious rooting: $73-86 \%$, depth of latching included the areola: $73-80 \%$, latching-on for longer than six minutes: 46 $53 \%$, long sucking bursts: $40-67 \%$, longest sucking burst of more than 21 sucks: $33-$ $36 \%$ and showing at least some swallowing $73-80 \%$. Fewer infants displayed the most mature behaviours in this study than in Nyqvist et al.'s (1996) study for rooting $(16.4 \%)$, depth of latching $(6.8 \%)$ and latching-on for more than six minutes $(23.4 \%)$.

The lower percentage of infants exhibiting mature behaviours observed in this study when compared to Nyqvist et al. (1996) may be due to variations in participants' chronological age at the time of assessment and the presence of infants with 
morbidities in the sample. Nyqvist et al. (1996) did not specify the chronological age of their participants at the time of assessment, or indicate whether infants with morbidities were included or excluded from their sample. However, their results were similar to those obtained in this study for the percentage of LPIs achieving long sucking bursts (46.6\%), and showing at least some swallowing (87.7\%). When comparing these percentages to the breastfeeding characteristics of term infants, Nyqvist et al. (1996) found that a higher percentage of term infants achieved mature breastfeeding behaviour for each breastfeeding characteristic than LPIs. Thus, although several of the LPIs breastfeeding characteristics in this study were within the norms for term infants, term infants may nevertheless have the potential for exhibiting more mature breastfeeding characteristics. This serves to emphasise that LPIs should not be treated as term infants, or expected to perform on par with term infants.

4.2.3. Inefficient milk transfer. Many of the breastfeeding characteristics which were evident in this study's sample of LPIs appear to be associated with poor milk transfer, according to literature. No or shallow latching-on, infrequent swallowing in half of the participants and the possibility that participants were exhibiting nonnutritive sucking, rather than nutritive sucking at the breast, are all breastfeeding characteristics which may contribute to inefficient milk transfer (Cadwell, 2007; Wolf \& Glass, 1992). Thus, when an infant is an inefficient feeder, shorter breastfeeding sessions (such as in the present study), raise a concern that oral intake by direct breastfeeding alone will not be sufficient for adequate nutrition, hydration and weightgain.

Indeed, the results of this study suggest that direct breastfeeding alone was not sufficient to meet the needs of this sample of LPIs, given the high percentage receiving supplementary tube-feeding (26\%) and cup-feeding $(86.3 \%)$ at the time of data collection. Previous research has also found that supplementary feeding in addition to direct breastfeeding was required in LPIs. Lapillonne, O'Connor, Wang and Rigo (2013) found that 33\% of LPIs in their study required some form of supplementary feeding in addition to direct breastfeeding. The higher percentage of infants receiving supplementary feeding in the current study, may in part be due to 
the volume-driven approach followed in the KMC unit, where top-up cup-feeding after each direct breastfeeding session is common to ensure adequate milk intake for weight-gain. While this volume-driven supplementation may have increased the percentage of participants receiving cup-feeding in the present study, it nevertheless indicates a concern by the doctors and dieticians working with LPIs that intake by direct breastfeeding alone would be insufficient for adequate weight maintenance or weight gain. Poor milk intake may also play a role in the development of hyperbilirubinaemia (Kuzniewicz et al., 2013; Meier et al., 2013). While it is true that hyperbilirubinaemia may be as a result of physiological factors, it may also be as a result of poor feeding and decreased milk intake (Kuzniewicz et al., 2013).The large number of participants presenting with hyperbilirubinaemia in this study also suggests that adequate breast milk intake was insufficient (Meier et al., 2007). Radtke (2012) states that regular monitoring of milk intake and hyperbilirubinaemia is imperative in LPIs.

Despite the smaller percentage of infants requiring supplementary feeding in addition to direct breastfeeding in the study by Lapillonne et al. (2013) than in the present study, the authors concluded that direct breastfeeding alone may not be sufficient to meet the nutritional needs of LPIs, given their tendency towards breastfeeding difficulties. Other studies support this notion (Shapiro-Mendoza et al., 2006; Tomashek et al., 2006). Research indicates that LPIs who are breastfeeding tend to be more likely than non-breastfeeding LPIs, to present with weight-gain difficulties, jaundice and feeding difficulties (Shapiro-Mendoza et al., 2006; Tomashek et al., 2006). It has also been found that LPIs who were directly breastfeeding without receiving supplementary feeds by alternative means, lost more weight than those who received supplementary feeding in addition to direct breastfeeding (Mattsson et al., 2015). However, Radtke (2012) states that the difficulties LPIs appear to present with when directly breastfeeding without supplementary feeds by other means, are related to the breastfeeding process, rather than the breast milk itself.

Thus, the practice of supplementing direct breastfeeding with expressed breast milk via cup-feeding, as in the KMC unit, may be a valuable intervention for LPIs. In this way, the infants receive only breast milk, adhering to the global standard for optimal 
health and development of any child (WHO, 2003a), and by using cups rather than bottles, the unit adheres to the BFHI guidelines (WHO, 2009). Furthermore, literature has shown cup-feeding to be a viable option in LPIs and has also shown cup-feeding to promote easier transitioning to breastfeeding than bottle-feeding (Briere, Lucas, McGrath, Lussier, \& Brownell, 2015; Yilmaz, Caylan, Karacan, Bodur, \& Gokcay, 2014). By providing supplementary cup-feeds in addition to direct breastfeeding, LPIs who may be at risk for poor milk intake at the breast are ensured sufficient milk intake for adequate nutrition and hydration.

However, Nyqvist (2013b) states that the practice of regular top-up feeding (including cup-feeding) in addition to breastfeeding to ensure adequate volume intake at scheduled feeds, may be counterproductive for preterm infants who are breastfeeding. She refers to a study by Funkquist, Tuvemo, Jonsson, Serenius and Nyqvist (2007), which found that infants semi-demand breastfeeding, rather than breastfeeding at scheduled times, and who did not receive top-up supplementary feeding, had better milk intake at the breast than infants receiving top-up feeding. It appeared that allowing infants to breastfeed more frequently at the breast, resulted in greater milk intake at the breast than when employing top-up feeding after each scheduled breastfeeding session. Nyqvist (2013b) stated that cup-feeding may be used when an infant is tired, or during the night, but that allowing frequent semidemand, cue-based breastfeeding rather than regular top-up cup-feeding, may promote a more rapid increase in the volume of milk taken at the breast than when top-up feeds are provided. While this practice may increase the risk of weight-loss in participants, Mattsson et al. (2015) state that in well-controlled environments in which regular monitoring of weight and milk intake takes place, direct breastfeeding without supplementary tube-feeding or cup-feeding need not be a risk for weight-loss in infants.

Thus, literature suggests that more frequent, cue-based breastfeeding may be an option worth considering in the care of LPIs, not only for the benefits for increased milk intake for infants, but also for the positive impact on lactation (Radtke, 2012). As suggested by Nyqvist (2013b), occasional cup-feeding to supplement these more 
frequent breastfeeding sessions can still be employed when an infants is fatigued, or during the night.

4.2.4. Avoiding lactation difficulties. Investigation into this aspect was not the aim of the present study, however, it was noted that medical professionals documented only a small percentage of mothers with lactation difficulties in this sample (5.5\%). It was surprising that lactation difficulties were not more prevalent in the sample, as mothers of LPIs have been found to be at higher risk for lactation difficulties than the mothers of term infants (Adamkin, 2006; Meier et al., 2007; Radtke, 2012). This small percentage of lactation difficulties may be due to the hospital's practice of allowing rooming-in of the mothers, skin-to-skin care and the encouragement of expressing breast milk which may have reduced the risk for lactation difficulties. These practices were implemented as soon after birth as possible, and were thus implemented while infants were still in the NICU and had not yet been admitted to the KMC unit. The value of these interventions for breastfeeding has been previously addressed in literature, indicating the KMC unit is adhering to evidence-based practices in this regard (Briere et al., 2015; Meier et al., 2007; Meier et al., 2013; Moore et al., 2012). Allowing skin-to-skin care and promoting expressed breast milk are interventions which should be considered in the care of LPIs, as lactation difficulties in mothers of LPIs have been shown to impact on the success of breastfeeding (Raju et al., 2006).

4.2.5. The value of experience. Although this study did not longitudinally assess the development of breastfeeding characteristics of the participants, the trend of the results suggested that the older, more experienced infants exhibited more mature breastfeeding characteristics. This is in accordance with literature, as Nyqvist (2013a) states that an infant's feeding skills are triggered by exposure to breastfeeding. Amaizu, Shulman, Schanler and Lau (2008), as well as Bingham (2009) agree, stating that training enhances sucking skills. Lau et al. (2000) found that during bottle-feeding, there was a significant positive correlation between the PMA of young preterm infants and sucking characteristics, which also suggests that feeding improves as an infant matures. 
In summary, this literature highlights that LPIs should be allowed to "practice" direct breastfeeding or suckling at the breast even if receiving tube-feeding or cup-feeding as a primary source of nutrition. The literature discussed above suggests that allowing infants to gain experience with direct breastfeeding may contribute to the development of more successful direct breastfeeding over time. In this case, the KMC unit's practices are again in accordance with literature, as suckling at the breast is encouraged, even when infants are receiving feeds via tubes or cups (Van Rooyen, 2007). The concept of improved direct breastfeeding with increased experience is one supported by literature. However, as the present study's results could only reveal trends which appear to support this concept, rather than statistical significance, it is recommend that further research be undertaken in order to further investigate the role of experience and chronological age in direct breastfeeding in LPIs.

4.2.6. The importance of a quiet environment. Successful oral feeding requires adequate behavioural state organisation (Delaney \& Arvedson, 2008), and preterm infants are easily overstimulated (Nyqvist, 2013a). This tendency to become overstimulated would impact on behavioural state readiness for feeding. Results of this study suggest that a disturbing environment may have impacted on the participants' breastfeeding characteristics. In this study, $45.2 \%$ of infants were being breastfed when the unit was not quiet or private enough. The open-dormitory set-up in the KMC unit may thus negatively impact on direct breastfeeding, despite its advantages of creating a sense of community and support for the mothers. In order to address this, every attempt should be made to maintain a quiet environment when breastfeeding LPIs in the KMC unit.

4.2.7. The impact of additional medical factors. In addition to behavioural state and the environment, many other medical conditions and risk factors may have impacted on the breastfeeding characteristics observed in this sample. A number of participants' case histories revealed factors such as being one of a twin, birth by caesarian section, RDS, SGA/IUGR, hyperbilirubinaemia, congenital disorders and craniofacial anomalies, which may also have contributed to the breastfeeding difficulties observed. 
Multiple births are more common in LPIs than in term infants (Natile et al., 2014). LPIs who are not single infants, are also found to be at a higher risk of morbidity (Melamed et al., 2009) and pulmonary disease (Natile et al., 2014), which may impact on feeding success. However, White-Traut et al. (2013) did not find significant differences between multiple births and single births, and oral feeding progression.

With regards to birth by caesarean section, in a large study, one third of LPIs were born by means of a caesarean section (Petrini et al., 2009), and LPIs born by caesarean section were at increased risk for neonatal morbidity (Melamed et al., 2009) and pulmonary dysfunction (Horgan, 2015). Increased morbidities and respiratory dysfunction may impact on feeding success, as cardiorespiratory stability is required for successful oral feeding (Lefton-Greif \& Arvedson, 2016). Preterm infants born by normal birth achieved independent oral feeding three days sooner than those born by caesarean section, also indicating that birth by caesarean section may be a risk for feeding difficulties (Van Nostrand, Bennett, Coraglio, Guo, \& Muraskas, 2015).

Higher rates of RDS are also found in LPIs than in term infants (5.3\% versus $0.45 \%$ )(Teune et al., 2011), and one study found as many as $14 \%$ of LPIs were diagnosed with respiratory distress (Giannì, Roggero, et al., 2015). As mentioned, respiratory stability is required for successful oral feeding (Lefton-Greif \& Arvedson, 2016), and thus the presence of RDS would negatively impact on breastfeeding. The presence of respiratory difficulties has also been strongly associated with the time to the first oral feeding in infants between 32 and 36 weeks GA (Jackson, Kelly, Mccann, \& Purdy, 2016). LPIs with respiratory distress were found to be at risk for requiring nutritional support (Giannì, Roggero, et al., 2015). Both these studies highlight the negative impact of respiratory difficulties on oral feeding.

Studies have also found that LPIs are more likely to be SGA than term infants (14.8 vs 9.3\%) (Natile et al., 2014). Being SGA can be a risk factor for neonatal mortality, and a positive correlation between being SGA and achieving full oral feeding has been found (Giannì, Sannino, et al., 2015; Pulver, Guest-Warnick, Stoddard, Byington, \& Young, 2009). Additionally, a significant association has been found 
between IUGR and oesophageal dysphagia in infants of 32 weeks GA and older (Pike, Pike, Kritzinger, Krüger, \& Viviers, 2016).

Higher levels of hyperbilirubinaemia have also been found in LPIs. A total of $17.4 \%$ of LPIs versus $9.6 \%$ of term infants were diagnosed with jaundice in a study by Bird et al. (2010). Teune et al. (2011) found that a higher percentage of LPIs had jaundice that required phototherapy than term infants. Ludwig (2007) states that jaundice may contribute to fatigue and reduced alertness, which may play a role in worsening feeding difficulties. Kuzniewicz et al. (2013) agree, stating that although LPIs may have physiological factors that predispose them to jaundice, jaundice may also be related to poor feeding. This may result in a cycle of difficulties, where jaundice contributes to fatigue, which contributes to poor milk intake, with resultant higher levels of jaundice (Meier et al., 2007).

Higher rates of congenital malformations have been found in preterm infants than in term infants (Honein et al., 2009; Kugelman \& Colin, 2013). It is well known that craniofacial abnormalities place infants at risk for feeding difficulties (Miller, 2009; Rogers \& Arvedson, 2005).

In this study, infants with the above-mentioned medical factors, were not excluded from the sample, in order to provide a holistic view of LPIs' breastfeeding characteristics in the KMC unit. As the discussion above indicates, factors other than the infants' GA, or chronological age may have impacted on the breastfeeding characteristics observed in this population of LPIs. The results of this study may represent the breastfeeding characteristics of particularly vulnerable LPIs, due to the fact that infants in a KMC unit are more likely to have medical complications than LPIs immediately discharged. The presence of these medical factors in many of the participants may have contributed to more breastfeeding difficulties than would be typical in healthy LPIs. Nevertheless, these medical factors cannot be ignored, as LPIs have a higher likelihood of presenting with many of these conditions, with a resultant increased likelihood of presenting with breastfeeding difficulties. The impact that the above-mentioned conditions can have on breastfeeding further emphasises that healthcare professionals should be vigilant for breastfeeding 
difficulties in LPIs, particularly if they present with the above-mentioned medical complications that require advanced knowledge of SLTs and other team members. Further investigation into the impact of these medical conditions on breastfeeding characteristics in LPIs is still required.

\subsection{Limitations}

A number of limitations should be mentioned. Firstly, when selecting participants, the GA of the infant was recorded based on the New Ballard Score, which is not as reliable as sonars for determining GA (Ballard et al., 1991). However, in many government hospitals in South Africa, ante-natal sonars are not readily available and thus medical professionals are trained and have experience in using the New Ballard Score for determining GA. Secondly, information in patient files was not always complete, resulting in missing values which may have impacted on the results obtained. Some case history items were based on maternal report, which may not always be accurate, especially when reporting on aspects such as level of education.

Additionally, the PIBBS that was used as the outcomes measure to collect data, was based on direct observation of a mother and infant. Although observation is considered the least invasive method of assessing breastfeeding behaviour (Nyqvist et al., 1996), the presence of an observer may nevertheless have an impact on the mother's and infant's behaviour. Furthermore, given that it is an observational scale, results are based on the perceptions of an observer, which may be subjective. In order to minimise subjectivity during observations, only SLTs trained in the assessment of breastfeeding were involved in recording the observations of the infants' breastfeeding behaviours.

Another consideration is the fact that results were based on an isolated breastfeeding session, which may not provide an accurate view of the average breastfeeding performance of the participants. The observation may have taken place at a particularly successful, or particularly poor breastfeeding session. 
In addition, the sample size in this study limited the analysis that could be carried out, particularly when determining associations and significant differences between factors and groups. A larger sample may have allowed for determining the statistical significance of differences in breastfeeding characteristics in different environments (quiet or noisy), with different general behaviours of the participants, and different levels of experience with breastfeeding. At present, the sample size only allowed for discussion regarding trends noted, and not statistical significance, with the exception of comparison between chronological age-groups. However, this moderate sample size may still allow tentative generalisation to similar populations, albeit not to LPIs outside of KMC units.

\subsection{Future research directions}

To date, no original research could be found regarding the breastfeeding characteristics of LPIs in a KMC unit. Thus, this study served to provide exploratory information regarding breastfeeding characteristics in this population. The results of the study served to raise a number of additional questions regarding breastfeeding in LPIs that require further investigation.

A similar study that includes a larger sample size would be valuable to confirm the reliability and validity of results obtained. A larger sample size would also allow for more in-depth analysis of the data, to determine whether significant differences or associations exist between groups. More in-depth analysis could allow investigation into which risk- and medical factors, as well as infant behaviours and environmental conditions could be statistically associated with mature or immature breastfeeding characteristics in LPIs. Risk factors for potential breastfeeding difficulties in LPIs could then be determined. However, it is recommended that in future research using the PIBBS, that a longer period of training of raters be undertaken prior to data collection, which may facilitate greater clarity and consistency in scoring by raters.

The results highlighted a number of breastfeeding characteristics, which previous literature has shown to be associated with inefficient milk transfer. Further investigation into the volumes and rates of milk transfer during breastfeeding in LPIs 
may provide additional information regarding this aspect. The results raised questions regarding the specific sucking characteristics of LPIs. Sucking-burst length was recorded in this study, but further investigation into sucking strength and whether sucking patterns were nutritive or non-nutritive is required. Further investigation into the application of cue-based breastfeeding as opposed to regular top-up cup-feeding to improve milk intake in this context should also undergo further investigation. As mentioned, the trends in the results of the current study suggested that increased chronological age and experience with direct breastfeeding improved breastfeeding skills. A longitudinal study may be valuable to further investigate the impact of chronological age and experience on LPIs' breastfeeding characteristics.

The purpose of this study was to descriptively represent the breastfeeding characteristics of LPIs in a KMC unit. However, including full-term infants and moderately- and extremely premature infants into a future study as controls may allow for comparison between these groups. This may provide more information regarding the degree of maturity of breastfeeding characteristics in LPIs.

This study was intentionally conducted on LPIs in a KMC unit, but it did not evaluate the impact of KMC on breastfeeding characteristics in this population. Further information regarding the impact of KMC on specific breastfeeding characteristics in this population may be valuable. Results of this study may have been considerably different, had it included healthy LPIs who were immediately discharged from hospital after birth. Including these infants in a future study, may allow for results that are more readily generalisable to LPIs outside of KMC units.

\subsection{Conclusion}

In a KMC unit, this sample of LPIs, presented with specific breastfeeding characteristics, some of which may promote successful breastfeeding, and others which may contribute to subtle direct breastfeeding difficulties and inefficiencies. Several breastfeeding characteristics may promote or hinder successful breastfeeding depending on the infant. 
Positive breastfeeding characteristics included that almost all participants were latching-on, that participants exhibited a mean longest sucking burst length within the norm for term infants and that approximately half the participants exhibited repeated swallowing. Another positive breastfeeding characteristic was that there appeared to be a trend towards more successful breastfeeding in infants who were older and had more experience breastfeeding, suggesting that practice may facilitate more successful breastfeeding.

Breastfeeding characteristics which may have contributed to subtle difficulties included that participants exhibited shallow latching, and although approximately half the participants were swallowing repeatedly, half were not swallowing or swallowing only occasionally. Many participants were crying and fussing during breastfeeding, and participants tended to be sensitive to environmental disturbance.

Breastfeeding characteristics which may indicate successful or poor breastfeeding, depending on the infant, include that participants were held for breastfeeding for short periods, and that most participants exhibited the breastfeeding behaviour of closed eyes and no body movements.

These breastfeeding characteristics, considered holistically, did not point to severe breastfeeding difficulties, but raised concerns regarding the efficiency of breastfeeding in this sample. Knowledge of the specific breastfeeding characteristics which highlight subtle breastfeeding difficulties in this population, may prevent unrealistic expectations of mothers and healthcare professionals working with LPIs in a KMC unit. This knowledge may also allow for more specific, individualised breastfeeding support and intervention for this population who may be at risk for cognitive and behavioral difficulties well-beyond infancy (Brumbaugh et al., 2016). The increased knowledge may be particularly important for SLTS, whose role is to identify and treat feeding difficulties in collaboration with other team members, as well as to provide mother-infant communication interaction, which is a beneficial adjacent to KMC programmes (ASHA, 2017; Kritzinger \& Van Rooyen, 2014). This individualised support and early intervention may also assist in preventing the negative cyclic implications of poor breastfeeding on milk intake, vulnerable infant 
physiological status, maternal anxiety, maternal milk supply and bonding.

Breastfeeding also supports the normal development and growth and functioning of the oral-facial mechanisms, and thus early intervention to promote successful breastfeeding may prevent difficulties later on in development, which may require more extensive treatment (Genna \& Sandora, 2013).

Engle et al. (2007) refers to LPIs as a population at risk. Since then, much literature, and the results of the present study confirm this statement. LPIs are a vulnerable population, whose risk for breastfeeding difficulties should not be overlooked. 


\section{References}

Adamkin, D. H. (2006). Feeding problems in the late preterm infant. Clinics in Perinatology, 33, 831-837. http://doi.org/10.1016/j.clp.2006.09.003.

Amaizu, N., Shulman, R. J., Schanler, R. J., \& Lau, C. (2008). Maturation of oral feeding skills in preterm infants. Acta Paediatrica, 97, 61-67. http://doi.org/10.1111/j.1651-2227.2007.00548.

American Academy of Pediatrics. (2004). Age terminology during the perinatal period: Policy statement. Pediatrics, 114(5), 1362-1364. http://doi.org/10.1542/peds.2004-1915.

American Speech-Language-Hearing Association. (2017). Pediatric dysphagia. Retrieved April 5, 2017, from http://www. asha.org/PRPSpecificTopic. aspx?folderid=8589934965\&section=Ov erview.

Ballard, J. L., Khoury, J. C., Wedig, K., Wang, L., Eilers-Welsman, B. L., \& Lipp, R. (1991). New Ballard Score, expanded to include extremely premature infants. Journal of Pediatrics, 119(3), 417-23.

Bingham, P. M. (2009). Deprivation and dysphagia in premature infants. Journal of Child Neurology, 24(6), 743-749. http://doi.org/10.1177/0883073808329530.

Bird, T. M., Bronstein, J. M., Hall, R. W., Lowery, C. L., Nugent, R., \& Mays, G. P. (2010). Late preterm infants: Birth outcomes and health care utilization in the first year. Pediatrics, 126(2), e311-e319. http://doi.org/10.1542/peds.2009-2869.

Briere, C. E., Lucas, R., McGrath, J. M., Lussier, M., \& Brownell, E. (2015).

Establishing breastfeeding with the late preterm infant in the NICU. Journal of Obstetric, Gynecologic, and Neonatal Nursing, 44, 102-113. http://doi.org/10.1111/1552-6909.12536.

Brumbaugh, J. E., Conrad, A. L., Lee, J. K., Devolder, I. J., Zimmerman, M. B., Magnotta, V. A., ... Nopoulos, P. C. (2016). Trajectory in Children Born Late 
Preterm, 80(February), 1-7. http://doi.org/10.1038/pr.2016.82.

Cadwell, K. (2007). Latching-on and suckling of the healthy term neonate:

Breastfeeding assessment. Journal of Midwifery and Women's Health, 52(6), 638-642. http://doi.org/10.1016/j.jmwh.2007.08.004.

Capilouto, G. J., Cunningham, T., Frederick, E., Dupont-Versteegden, E., Desai, N., \& Butterfield, T. A. (2014). Infant behavior and development: Comparison of tongue muscle characteristics of preterm and full term infants during nutritive and nonnutritive sucking. Infant Behavior and Development, 37(3), 435-445. http://doi.org/10.1016/j.infbeh.2014.05.010.

Claassen, D., Pieterse, J., Van der Linde, J., Kruger, E., \& Vinck, B. (2016). Risks for communication delays and disorders in infants in an urban primary healthcare clinic. South African Journal of Child Health, 10(1), 25-28. http://doi.org/10.7196/SAJCH.2016.v106i1.944.

Cleaveland, K. (2010). Feeding challenges in the late preterm infant. Neonatal Network, 29(1), 37-41.

Delaney, A. L., \& Arvedson, J. C. (2008). Development of swallowing and feeding: Prenatal through first year of life. Developmental Disabilities Research Reviews, 14, 105-117. http://doi.org/10.1002/ddrr.16.

Demirci, J. R., Happ, M. B., Bogen, D. L., Albrecht, S. A., \& Cohen, S. M. (2015). Weighing worth against uncertain work: The interplay of exhaustion, ambiguity, hope and disappointment in mothers breastfeeding late preterm infants.

Maternal \& Child Nutrition, 11, 59-72. http://doi.org/10.1111/j.17408709.2012.00463.

Engle, W. A., Tomashek, K. M., \& Wallman, C. (2007). "Late-preterm” infants: A population at risk. American Academy of Pediatrics, 120(6), 1390-1401. http://doi.org/10.1542/peds.2007-2952.

Escobar, G. J., Clark, R. H., \& Greene, J. D. (2006). Short-term outcomes of infants born at 35 and 36 weeks gestation: We need to ask more questions. Seminars 
in Perinatology, 30, 28-33. http://doi.org/10.1053/j.semperi.2006.01.005.

Fleiss, J., Levin, B., \& Paik, M. C. (2003). Statistical methods for rates and proportions (3rd Edition). John Wiley \& Sons, Inc. http://doi.org/10.1198/tech.2004.s812.

Funkquist, E., Tuvemo, T., Jonsson, B., Serenius, F., \& Nyqvist, K. (2007). Milk for small infants. Acta Paediatrica, 96(4), 596-9.

Furman, L., \& Minich, N. (2004). Efficiency of breastfeeding as compared to bottlefeeding. Journal of Perinatology, 24, 706-13. http://doi.org/10.1038/sj.jp.7211175.

Geddes, D. T., Kent, J. C., Mitoulas, L. R., \& Hartmann, P. E. (2008). Tongue movement and intra-oral vacuum in breastfeeding infants. Early Human Development, 84, 471-477. http://doi.org/10.1016/j.earlhumdev.2007.12.008.

Genna, C. W., \& Sandora, L. (2013). Breastfeeding: Normal sucking and swallowing. In C. W. Genna (Ed.), Supporting Sucking Skills in Breastfeeding Infants (2nd Edition, pp. 1-48). Burlington: Jones \& Bartlett Learning.

Gewolb, I. H., \& Vice, F. L. (2006). Maturational changes in the rhythms, patterning, and coordination of respiration and swallow during feeding in preterm and term infants. Developmental Medicine and Child Neurology, 48, 589-594. http://doi.org/10.1017/S001216220600123.

Giannì, M. L., Roggero, P., Piemontese, P., Liotto, N., Orsi, A., Amato, O., ... Mosca, F. (2015). Is nutritional support needed in late preterm infants? BMC Pediatrics, 15, 194-8. http://doi.org/10.1186/s12887-015-0511-8.

Giannì, M. L., Sannino, P., Bezze, E., Plevani, L., Cugno, N., Roggero, P., .. Mosca, F. (2015). Effect of co-morbidities on the development of oral feeding ability in pre-term infants: A retrospective study. Scientific Reports, 5, 1-8. http://doi.org/10.1038/srep16603.

Goldfield, E. C., Richardson, M. J., Lee, K. G., \& Margetts, S. (2006). Coordination of sucking, swallowing, and breathing and oxygen saturation during early infant 
breast-feeding and bottle-feeding. Pediatric Research, 60(4), 450-455.

http://doi.org/10.1203/01.pdr.0000238378.24238.9d.

Gouyon, J. B., lacobelli, S., Ferdynus, C., \& Bonsante, F. (2012). Neonatal problems of late and moderate preterm infants. Seminars in Fetal and Neonatal Medicine, 17, 146-152. http://doi.org/10.1016/j.siny.2012.01.015.

Goyal, N. K., Attanasio, L. B., \& Kozhimannil, K. B. (2014). Hospital care and early breastfeeding outcomes among late preterm, early-term, and term infants. Birth, 41(4), 330-338. Retrieved from http://ovidsp.ovid.com/ovidweb.cgi?T=JS\&PAGE=reference\&D=medl\&NEWS=N $\& A N=25294061$.

Hackman, N. M., Alligood-Percoco, N., Martin, A., Zhu, J., \& Kjerulff, K. H. (2016). Reduced breastfeeding rates in firstborn late preterm and early term infants. Breastfeeding Medicine, 11(3), 119-125. http://doi.org/10.1089/bfm.2015.0122.

Hake-Brooks, S. J., \& Anderson, G. C. (2008). Kangaroo care and breastfeeding of mother-preterm infant dyads 0-18 months: A randomized, controlled trial. Neonatal Network, 27(3), 151-159.

Hallgren, K. A. (2012). Computing inter-rater reliability for observational data: An overview and tutorial. Tutorials in Quantitative Methods for Psychology, 8(1), 23-34. http://doi.org/10.20982/tqmp.08.1.p023.

Havenga, Z., \& Joubert, D. (2015). The feasibility of the Preterm Breastfeeding Behavior Scale in a kangaroo mother care unit. University of Pretoria: Unpublished.

Honein, M. A., Kirby, R. S., Meyer, R. E., Xing, J., Skerrette, N. I., Yuskiv, N., ... Sever, L. E. (2009). The association between major birth defects and preterm birth. Maternal and Child Health Journal, 13(2), 164-175. http://doi.org/10.1007/s10995-008-0348-y.

Horgan, M. J. (2015). Management of the late preterm infant: Not quite ready for prime time. Pediatric Clinics of North America, 62, 439-451. 
http://doi.org/10.1016/j.pcl.2014.11.007.

Jackson, B. N., Kelly, B. N., Mccann, C. M., \& Purdy, S. C. (2016). Predictors of the time to attain full oral feeding in late preterm infants. Acta Paediatrica, 105, 1-6. http://doi.org/10.1111/apa.13227.

Kaur, B., \& Kumar, P. (2011). Effect of initiation of breast-feeding within one hour of the delivery on "maternal-infant bonding." Nursing and Midwifery Research Journal, 7(3), 99-109.

Kritzinger, A., \& Van Rooyen, E. (2014). The effect of formal, neonatal communication-intervention training on mothers in kangaroo care. African Journal of Primary Health Care \& Family Medicine, 6(1), 1-9.

Kugelman, A., \& Colin, A. A. (2013). Late preterm infants: Near term but still in a critical developmental time period. Pediatrics, 132(4), 741-751. http://doi.org/10.1542/peds.2013-1131.

Kuzniewicz, M. W., Parker, S. J., Schnake-Mahl, A., \& Escobar, G. J. (2013). Hospital readmissions and emergency department visits in moderate preterm, late preterm, and early term infants. Clinics in Perinatology, 40, 753-775. http://doi.org/10.1016/j.clp.2013.07.008.

Lapillonne, A., O’Connor, D. L., Wang, D., \& Rigo, J. (2013). Nutritional recommendations for the late-preterm infant and the preterm infant after hospital discharge. Journal of Pediatrics, 162, S90-100. http://doi.org/10.1016/j.jpeds.2012.11.058.

Lau, C., Alagugurusamy, R., Schanler, R. J., Smith, E. O., \& Shulman, R. J. (2000). Characterization of the developmental stages of sucking in preterm infants during bottle feeding. Acta Paediatrica, 89(7), 846-852. http://doi.org/10.1111/j.1651-2227.2000.tb00393.

Lau, C., Hurst, N. M., Smith, E. O., \& Schanler, R. J. (2007). Ethnic/racial diversity, maternal stress, lactation and very low birthweight infants. Journal of Perinatology, 27, 399-408. http://doi.org/10.1038/sj.jp.7211770. 
Leedy, P. D., \& Ormrod, J. E. (2014). Practical research: Planning and design (10th Edition). Harlow: Pearson Education Limited.

Lefton-Greif, M. A., \& Arvedson, J. C. (2016). Pediatric feeding/swallowing:

Yesterday, today, and tomorrow. Seminars in Speech and Language, 37, 298309.

Ludwig, S. M. (2007). Oral feeding and the late preterm infant. Newborn \& Infant Nursing Reviews, 7(2), 72-75. http://doi.org/10.1053/j.nainr.2007.05.005.

Mahmood, I., Jamal, M., \& Khan, N. (2011). Effect of mother-infant early skin-to-skin contact on breastfeeding status: A randomized controlled trial. Journal of the College of Physicians and Surgeons Pakistan, 21(10), 601-605. http://doi.org/10.2011/JCPSP.601605.

Mattsson, E., Funkquist, E., Wickström, M., Nyqvist, K. H., \& Volgsten, H. (2015). Healthy late preterm infants and supplementary artificial milk feeds: Effects on breast feeding and associated clinical parameters. Midwifery, 31(4), 426-431. http://doi.org/10.1016/j.midw.2014.12.004.

McDonald, S. W., Benzies, K. M., Gallant, J. E., McNeil, D., Dolan, S. M., \& Tough, S. C. (2013). A comparison between late preterm and term infants on breastfeeding and maternal mental health. Maternal \& Child Health, 17, 14681477. http://doi.org/10.1007/s10995-012-1153-1.

Medoff-Cooper, B., Bakewell-Sachs, S., Buus-Frank, M. E., \& Santa-Donato, A. (2006). The AWHONN near-term infant initiative: A conceptual framework for optimizing health for near-term infants. Journal of Obstetric, Gynecologic, and Neonatal Nursing, 34, 666-671. http://doi.org/10.1177/0884217505281873.

Medoff-Cooper, B., Bilker, W. B., \& Kaplan, J. M. (2001). Suckling behavior as a function of gestational age: A cross-sectional study. Infant Behavior and Development, 24, 83-94.

Meier, P. P., Furman, L. M., \& Degenhardt, M. (2007). Increased lactation risk for late preterm infants and mothers: Evidence and management strategies to 
protect breastfeeding. Journal of Midwifery and Women's Health, 52(6), 579587. http://doi.org/10.1016/j.jmwh.2007.08.003.

Meier, P., Patel, A., Wright, K., \& Engstrom, J. (2013). Management of breastfeeding during and after the maternity hospitalization for late preterm infants. Clinical Perinatology, 40(4), 689-705.

http://doi.org/10.1126/scisignal.2001449.Engineering.

Melamed, N., Klinger, G., Tenenbaum-Gavish, K., Herscovici, T., Linder, N., Hod, M., \& Yogev, Y. (2009). Short-term neonatal outcome in low-risk, spontaneous, singleton, late preterm deliveries. Obstetrics and Gynecology, 114(2), 253-260.

Miller, C. K. (2009). Updates on pediatric feeding and swallowing problems. Current Opinion in Otolaryngology \& Head and Neck Surgery, 17(3), 194-9. http://doi.org/10.1097/MOO.0b013e32832b3117.

Moore, E., Anderson, G. C., \& Bergman, N. (2012). Early skin-to-skin contact for mothers and their healthy newborn infants. Cochrane Database of Systematic Reviews, 5(3), 1-75. http://doi.org/10.1002/14651858.CD003519.pub2.

Natile, M., Ventura, M. L., Colombo, M., Bernasconi, D., Locatelli, A., Plevani, C., ... Tagliabue, P. (2014). Short-term respiratory outcomes in late preterm infants. Italian Journal of Pediatrics, 40, 52-62. http://doi.org/10.1186/1824-7288-40-52.

Nelson, L. K. (2017). Research in communication sciences and disorders: Methods for systematic enquiry (2nd Edition). San Diego: Plural Publishing.

Nyqvist, K. H. (2005). Breastfeeding support in neonatal care: An example of the integration of international evidence and experience. Newborn and Infant Nursing Reviews, 5(1), 34-48. http://doi.org/10.1053/j.nainr.2005.02.006.

Nyqvist, K. H. (2013a). Breastfeeding preterm infants. In C. W. Genna (Ed.), Supporting Sucking Skills in Breastfeeding Infants (2nd Edition, pp. 171-196). Burlington: Jones \& Bartlett Learning.

Nyqvist, K. H. (2013b). Lack of knowledge persists about early breastfeeding competence in preterm infants. Journal of Human Lactation, 29(3), 296-9. 
http://doi.org/10.1177/0890334413489774.

Nyqvist, K. H., Häggkvist, A., Hansen, M. N., Kylberg, E., Frandsen, A. L., Maastrup, R., ... Haiek, L. N. (2013). Expansion of the baby-friendly hospital initiative ten steps to successful breastfeeding into neonatal intensive care: Expert group recommendations. Journal of Human Lactation, 20(10), 1-10. http://doi.org/10.1177/0890334413489775.

Nyqvist, K. H., Rubertsson, C., Ewald, U., \& Sjödén, P. O. (1996). Development of the preterm infant breastfeeding behavior scale (PIBBS): A study of nursemother agreement. Journal of Human Lactation, 12(3), 207-219.

Nyqvist, K. H., Sjoden, P., \& Ewald, U. (1999). The development of preterm infants ' breastfeeding behavior. Early Human Development, 55, 247-264.

Oras, P., Thernström Blomqvist, Y., Nyqvist, K. H., Gradin, M., Rubertsson, C., Hellström-Westas, L., \& Funkquist, E. L. (2016). Skin-to-skin contact is associated with earlier breastfeeding attainment in preterm infants. Acta Paediatrica, 105, 783-789. http://doi.org/10.1111/apa.13431.

Petrini, J. R., Dias, T., Mccormick, M. C., Massolo, M. L., Green, N. S., \& Escobar, G. J. (2009). Increased risk of adverse neurological development for late preterm infants. The Journal of Pediatrics, 154, 169-176.e3. http://doi.org/10.1016/j.jpeds.2008.08.020.

Pike, C., Pike, M., Kritzinger, A., Krüger, E., \& Viviers, M. (2016). Risk profiles of infants $\geq 32$ weeks' gestational age with oropharyngeal and oesophageal dysphagia in neonatal care. South African Journal of Child Health, 10(2), 130-3. http://doi.org/10.7196/SAJCH.2016.v10i2.1051.

Pulver, L. S., Guest-Warnick, G., Stoddard, G. J., Byington, C. L., \& Young, P. C. (2009). Weight for gestational age affects the mortality of late preterm infants. Pediatrics, 123(6), e1072-e1077. http://doi.org/10.1542/peds.2008-3288.

Radtke, J. V. (2012). The paradox of breastfeeding-associated morbidity among late preterm infants. Journal of Obstetric, Gynecologic, and Neonatal Nursing, 40(1), 
Radzyminski, S. (2005). Neurobehavioural functioning and breastfeeding behaviour in the newborn. Journal of Obstetric, Gynecologic, and Neonatal Nursing, 34(3), 335-341. http://doi.org/10.1177/0884217505276283.

Raju, T. N. K., Higgins, R. D., Stark, A. R., \& Leveno, K. J. (2006). Optimizing care and outcome for late-preterm (near-term) infants: A summary of the workshop sponsored by the national institute of child health and human development. Pediatrics, 118(3), 1207-1214. http://doi.org/10.1542/peds.2006-0018.

Rayfield, S., Oakley, L., \& Quigley, M. A. (2015). Association between breastfeeding support and breastfeeding rates in the UK: A comparison of late preterm and term infants. BMJ Open, 5, 1-10. http://doi.org/10.1136/bmjopen-2015-009144.

Reinard, J. C. (Ed.). (2006). Communication Research Statistics (1st Edition). United States of America: Sage Publications Inc.

Rogers, B., \& Arvedson, J. (2005). Assessment of infant oral sensorimotor and swallowing function. MRDD Research Reviews, 11, 74-82. http://doi.org/10.1002/mrdd.20055.

Shapiro-Mendoza, C. K., \& Lackritz, E. M. (2012). Epidemiology of late and moderate preterm birth. Seminars in Fetal and Neonatal Medicine, 17, 120-125. http://doi.org/10.1016/j.siny.2012.01.007.

Shapiro-Mendoza, C. K., Tomashek, K. M., Kotelchuck, M., Barfield, W., Weiss, J., \& Evans, S. (2006). Risk factors for neonatal morbidity and mortality among "healthy", late preterm newborns. Seminars in Perinatology, 30, 54-60. http://doi.org/10.1053/j.semperi.2006.02.002.

Teune, M. J., Bakhuizen, S., Bannerman, C. G., Opmeer, B. C., Van Kaam, A. H., Van Wassenaer, A. G., ... Mol, B. W. J. (2011). A systematic review of severe morbidity in infants born late preterm. American Journal of Obstetrics and Gynecology, 205, 374.e1-9. http://doi.org/10.1016/j.ajog.2011.07.015.

The Academy of Breastfeeding Medicine. (2011). ABM clinical protocol number 10: 
Breastfeeding the late preterm infant (34 0/7 to $366 / 7$ weeks gestation). Breastfeeding Medicine, 6(3), 151-6. http://doi.org/10.1089/bfm.2011.9990.

Tomashek, K. M., Shapiro-Mendoza, C. K., Weiss, J., Kotelchuck, M., Barfield, W., Evans, S., ... Declercq, E. (2006). Early discharge among late preterm and term newborns and risk of neonatal morbidity. Seminars in Perinatology, 30(2), 61-8. http://doi.org/10.1053/j.semperi.2006.02.003.

Van Nostrand, S. M., Bennett, L. N., Coraglio, V. J., Guo, R., \& Muraskas, J. K. (2015). Factors influencing independent oral feeding in preterm infants. Journal of Neonatal-Perinatal Medicine, 8, 15-21. http://doi.org/10.3233/NPM15814045.

Van Rooyen, E. (2007). Infant feeding policy of the kangaroo mother care unit. Pretoria.

Van Rooyen, E. (2009). Ten years of kangaroo mother care at Kalafong Hospital. Pretoria.

Van Rooyen, E. (2016). Kalafong hospital paediatric protocol: Ward 4 and 10. Pretoria.

Van Rooyen, E. (2017a). Feeding difficulties in the kangaroo mother care unit. Pretoria: Personal communication.

Van Rooyen, E. (2017b). Infant feeding policy of the kangaroo mother care unit. Pretoria.

Van Rooyen, E., Pullen, A. E., Pattinson, R. C., \& Delport, S. D. (2002). The value of the kangaroo mother care unit at Kalafong Hospital. The Medicine Journal, April, 6-11.

Walker, M. (2008). Breastfeeding the late preterm infant. Journal of Obstetric, Gynecologic, and Neonatal Nursing, 37, 692-701.

Wang, M. L., Dorer, D. J., Fleming, M. P., \& Catlin, E. A. (2004). Clinical outcomes of near-term infants. Pediatrics, 114(2), 372-37. 
White-Traut, R., Pham, T., Rankin, K., Norr, K., Shapiro, N., \& Yoder, J. (2013). Exploring factors related to oral feeding progression in premature infants. Advanced Neonatal Care, 13(4), 288-294. http://doi.org/10.1097/ANC.0b013e31829d8c5a.

Wolf, L., \& Glass, R. P. (1992). Feeding and swallowing disorders in infancy: Assessment and management. Tucson: Therapy Skill Builders.

World Health Organization [WHO]. (2003a). Global strategy for infant and young child feeding. Geneva: WHO.

World Health Organization [WHO]. (2003b). Kangaroo mother care: A practical guide (Vol. 73). Retrieved from http://www.ncbi.nlm.nih.gov/pubmed/22585327.

World Health Organization [WHO]. (2009). Baby-Friendly Hospital Initiative. Retrieved from http://www.who.int/nutrition/publications/infantfeeding/bfhi.

World Health Organization [WHO]. (2012). HIV and infant feeding 2010: An updated framework for priority action. Geneva. Retrieved from http://www.who.int/maternal_child_adolescent/documents/9241590777/en/.

Yilmaz, G., Caylan, N., Karacan, C. D., Bodur, İ., \& Gokcay, G. (2014). Effect of cup feeding and bottle feeding on breastfeeding in late preterm infants: $A$ randomized controlled study. Journal of Human Lactation, 30(54), 174-9. http://doi.org/10.1177/0890334413517940.

Zanardo, V., Gambina, I., Begley, C., Litta, P., Cosmi, E., Giustardi, A., \& Trevisanuto, D. (2011). Psychological distress and early lactation performance in mothers of late preterm infants. Early Human Development, 87(4), 321-323. http://doi.org/10.1016/j.earlhumdev.2011.01.035. 


\section{Appendices}

Appendix A: Permission letter from neonatologist in KMC unit

Appendix B: Faculty of Humanities ethical clearance

Appendix C: Faculty of Health Sciences ethical clearance

Appendix D: Ethical clearance Kalafong Hospital

Appendix E: English parent information and informed consent

Appendix F: Northern Sotho parent information and informed consent

Appendix G: isiZulu parent information and informed consent

Appendix $\mathrm{H}$ : Case history capturing checklist

Appendix I: Preterm Infant Breastfeeding Behavior Scale

Appendix J: Proof of article submission to Breastfeeding Medicine

Appendix K: Decision letter Breastfeeding Medicine 
Appendix A:

Permission letter from neonatologist in KMC unit 


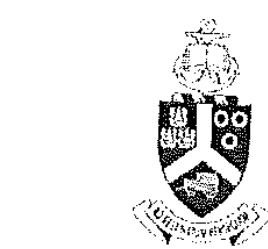

UNIVERSITEIT VAN PRETORIA

UNIVERSITY OF PRETORIA

YUNIBESITHI YA PRETORIA

Denkleters - Leading Minds $\cdot$ Dikgyopolo tšo Dihtoleft

Faculty of Humanities
Department of Speech-Language Pathology and Audiology

\section{March 2016}

Dr E van Rooyen

Head: Kangaroo Mother Care Unit

Ward 4 Kalafong Hospital

Dear Dr van Rooyen,

With this letter, we kindly request your permission to conduct research for a masters' study at Kalafong Hospital, in the Kangaroo Mother Care (KMC) ward.

\section{Title of the study}

Breastfeeding characteristics of late-preterm infants in a kangaroo mother care unit

\section{Primary Researcher}

Melissa Pike (Speech-Language Therapist)

\section{Research aim}

The aim of the study is to describe the breastfeeding characteristics of late-preterm infants in a KMC unit. The fact that there is limited recent research outlining potential difficulties that this population of infants may experience in feeding, is the rationale behind this research study.

\section{Ethical considerations}

- Ethical clearance will be applied for through the Faculty of Health Sciences and the Faculty of Humanities of the University of Pretoria prior to data collection.

- Informed consent will also be obtained from the mothers of all participants after providing them with written and oral information regarding the project. - Should it be deemed unsafe for an infant to continue the breastfeeding session, the feeding session will be
discontinued.

- Infants who are found to be presenting with breastfeeding difficulties during the observation, will be referred to the relevant medical professional should it be deemed necessary.

- The confidentiality of patient records will be maintained 


\section{Research Design}

A quantitative, descriptive research design will be employed.

\section{Research context}

Data collection will take place in the kangaroo mother care (KMC) ward at Kalafong Hospital.

\section{Participants}

Non-probability, convenient sampling will be used in order to select approximately 80 participants. Criteria for inclusion into the study are as follows:

- Each participant should fall into the category of being a late-preterm infant (having a gestational age of between 34 weeks and 0 days, and 36 weeks and 6 days).

- Should be in the KMC ward at the time of the assessment. The infant's feeding should be assessed within the first 7 days of birth.

- Should be able to breastfeed. Permission to attempt breastfeeding for infants who are tube feeding at the time, will be obtained from the doctor in the ward prior to the breastfeeding session.

\section{Materials and apparatus}

\section{Two checklists will be made use of:}

- The Risk Assessment checklist (Kritzinger, 1994) in order to record the case history of each participant.

- The Preterm Infant Breastfeeding Behaviour Scale (PIBBS) (Nyqvist et al., 1996). This is a validated tool, which is designed to be used by mothers and professionals to guide observations of preterm infants' breastfeeding (Nyquist et al., 1996).

\section{Procedures}

The study will incorporate two phases.

\section{Phase 1:}

Phase one of the study will be aimed at testing for inter-rater reliability (IRR) of the PIBBS. The two raters will be qualified speech-language therapists, one of which will be the primary researcher.

\section{Phase 2:}

Phase two of the study will entail completion of the PIBBS by only the primary researcher on further infants meet the terms for the inclusion criteria for this study. 


\section{Procedures within these phases:}

1. Obtain informed consent from the mother.

2. Review medical records to complete the case history using the Risk Assessment.

3. Interview the mother in order to complete aspects of the risk assessment not available in the medical file.

4. One complete breastfeeding session will be observed at any one of the normal feeding times adhered to in the ward or at the convenience of the mother. The observer will sit or stand in a position where the participant's face will be clearly visible.

\section{Further information}

Should you require further information, feel free to contact Melissa Pike on 0734315422

Please sign in the space provided in order to indicate that you grant permission for the research study to be carried out at Kalafong Hospital, in the KMC ward.

Yours sincerely,

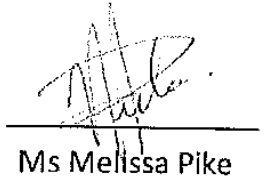

(Primary Researcher)

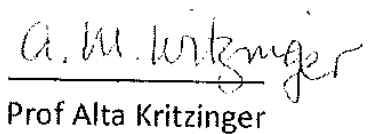

(Supervisor)

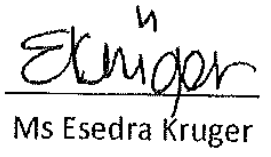

(Supervisor)

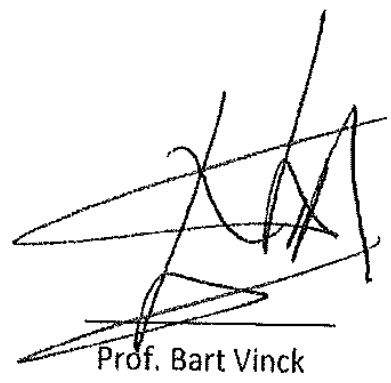

(Head of Department)

I hereby give permission that Melissa Pike, may conduct research for the study, "Breastfeeding characteristics of late-preterm infants in a kangaroo mother care unit", in the KMC unit, on the condition that ethical clearance be granted.

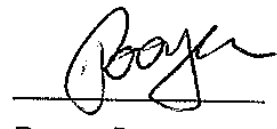

Dr van Rooyen

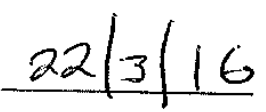

Date

Head of the KMC ward

Tel: 0124202355

Fax: 0124203517

mmw.up.ac.zo

Communication Pathology Building

Dept. of Speech-Language Pathology and Audiology

Corner of Lynnwood Road and Roper Street, Hatfield

Private Bag $\times 20$, Hatfield, 0028

barlvinck@up.ac.zo

University of Pretoria

PRETORIA

Republic of South Africa 
Appendix B:

Faculty of Humanities ethical clearance 
Faculty of Humanities Research Ethics Committee

29 August 2016

Dear Prof Vinck

Project:

Researcher:

Supervisor:

Department:

Reference number:
Breastfeeding in late-preterm infants in a kangaroo mother care unit

MC Pike

Prof A Kritzinger

Speech-Language Pathology and Audiology 11062500 (GW20160614HS)

Thank you for the response to the Committee's correspondence of 4 July 2016.

I have pleasure in informing you that the Research Ethics Committee formally approved the above study at an ad hoc meeting held on 29 August 2016. Data collection may therefore commence.

Please note that this approval is based on the assumption that the research will be carried out along the lines laid out in the proposal. Should your actual research depart significantly from the proposed research, it will be necessary to apply for a new research approval and ethical clearance.

The Committee requests you to convey this approval to the researcher.

We wish you success with the project.

Sincerely

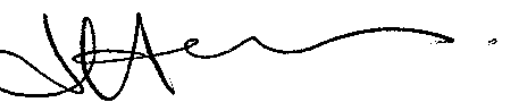

\section{Prof Maxi Schoeman}

Deputy Dean: Postgraduate and Research Ethics

Faculty of Humanities

UNIVERSITY OF PRETORIA

e-mail: tracey.andrew@up.ac.za

Kindly note that your original signed approval certificate will be sent to your supervisor via the Head of Department. Please liaise with your supervisor. 
Appendix C:

Faculty of Health Sciences ethical clearance 
The Research Ethics Committee, Faculty Health Sciences. University of Pretoria complies with $\mathrm{ICH}$ GCP guidelines and has US Federal wide Assurance.

- FWA 00002567, Approved dd 22 May 2002 and Expires 20 Oct 2016

- IRB 00002235 IORG0001762 Approved dd 22/04/2014 and Expires 22/04/2017.

UNIVERSITEIT VAN PRETORIA

UNIVERSITY OF PRETORIAA

YUNIBESITHI YA PRETORIA

Faculty of Health Sciences Research Ethics Committee

\section{Approval Certificate}

New Application

Ethics Reference No.: 333/2016

Title: Breastfeeding in late-preterm infants in a kangaroo mother care unit.

Dear Melissa Pike

The New Application as supported by documents specified in your cover letter dated 15/08/2016 for your research received on the 15/08/2016, was approved by the Faculty of Health Sciences Research Ethics Committee on its quorate meeting of 26/08/2016.

Please note the following about your ethics approval:

- Ethics Approval is valid for 1 year

- Please remember to use your protocol number (333/2016) on any documents or correspondence with the Research Ethics Committee regarding your research

- Please note that the Research Ethics Committee may ask further questions, seek additional information, require further modification, or monitor the conduct of your research.

Ethics approval is subject to the following:

- The ethics approval is conditional on the receipt of 6 monthly written Progress Reports, and

- The ethics approval is conditional on the research being conducted as stipulated by the details of all documents submitted to the Committee. In the event that a further need arises to change who the investigators are, the methods or any other aspect, such changes must be submitted as an Amendment for approval by the Committee.

We wish you the best with your research.

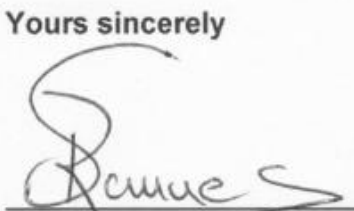

Dr R Sommers; MBChB; MMed (Int); MPharMed,PhD

Deputy Chairperson of the Faculty of Health Sciences Research Ethics Committee, University of Pretoria

The Faculty of Health Sciences Research Ethics Committee complies with the SA National Act 61 of 2003 as it pertains to health research and the United States Code of Federal Regulations Title 45 and 46. This committee abides by the ethical noms and principles for research, established by the Declaration of Helsinki, the South African Medical Research Council Guidelines as well as the Guidelines for Ethical Research: Principles Structures and Processes, Second Edition 2015 (Department of Health). 
Appendix D:

Ethical clearance Kalafong Hospital 


\section{GAUTENG PROVINCE}

KALAFONG HOSPITAL

PRIVATE BAG X396

PRETORIA

0001

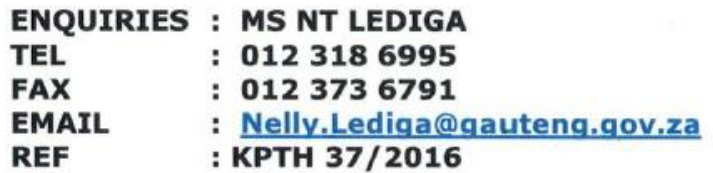

TO: MS MELISSA PIKE

\section{RE: PERMISSION TO CONDUCT RESEARCH}

TITLE: BREASTFEEDING CHARACTERISTICS OF LATE-PRETERM INFANTS IN A KANGAROO MOTHER CARE UNIT

Permission is hereby granted for the research to be conducted at Kalafong Provincial Tertiary Hospital.

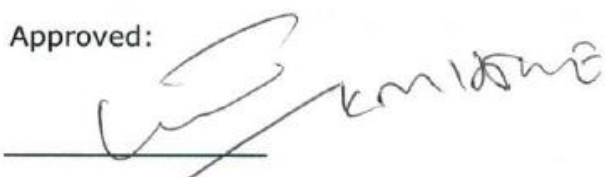

DR K.E LETEBELE-HARTELL

SENIOR MANAGER: MEDICAL SERVICES

DATE:

or O8 Mil


Appendix E:

English parent information and informed consent 


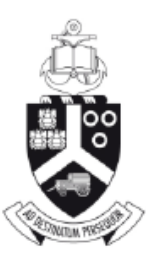

UNIVERSITEIT VAN PRETORIA

UNIVERSITY OF PRETORIA

YUNIBESITHI YA PRETORIA

Denkleiers • Leading Minds • Dikgopolo tša Dihlalefl

Faculty of Humanities

Department of Speech-Language Pathology and Audiology

\section{PARENT INFORMATION LEAFLET AND INFORMED CONSENT FORM}

STUDY TITLE: Breastfeeding in late-preterm infants in a kangaroo mother care unit.

PRINCIPAL INVESTIGATOR: Melissa Pike

INSTITUTION: University of Pretoria

DAYTIME AND AFTER HOURS TELEPHONE NUMBER(S):

Daytime numbers: 0734315422

Afterhours: 0734315422

DATE AND TIME OF FIRST INFORMED CONSENT DISCUSSION:

\begin{tabular}{|l|l|l|l|}
\hline & & & \\
\hline Day & Month & Year & Time \\
\hline
\end{tabular}

\section{Dear Patient}

\section{INTRODUCTION}

You and your child have been invited to volunteer for a research study. This information leaflet is to help you to decide if you would like to participate. Before you agree to take part in this study you should fully understand what is involved. If you have any questions, which are not fully explained in this leaflet, do not hesitate to ask the investigator. You should not agree for your baby to take part unless you are completely happy about all the procedures involved.

\section{WHAT IS THE PURPOSE OF THIS STUDY?}

This is a study to find out more about how babies born at 34 weeks until 36 weeks are breastfeeding. In order to do this, I need your permission to:

- Look at your child's hospital files to find information about your baby's history and how your baby has been doing since birth.

- Ask you questions about your history and about the pregnancy.

- To touch around your baby's mouth before you begin feeding your baby.

- Look at one normal breastfeeding session to see how your baby is behaving, sucking and swallowing while breastfeeding.

- To make notes while looking in the file and asking you questions, and while observing your baby breastfeeding.

- Have another speech therapist looking at how your baby is breastfeeding at the same time that I am looking. 
If you agree to take part in this study, it does not necessarily mean that your baby has a problem with breastfeeding. If your baby does not normally breastfeed, I will first get permission from your baby's doctor to try breastfeeding while I am observing. I am trained to work with babies and how they are feeding, and we will not force your baby to do something that your baby cannot do. I will also wash my hands before and after working with your baby, and you will not be separated from your baby during the study.

\section{HOW LONG WILL THE STUDY TAKE?}

If you decide for you and your baby to take part in the study, you will be one of about 80 mothers and babies who will take part in the study. If you agree to take part, I will only see you and your baby once while you are in the ward. The one time I see you, I will be with you for about 45 minutes:

- I will go through the file and ask you some questions about you and your baby. This will take about 10-15 minutes.

- I will then look at a complete breastfeeding session during one of your baby's feeding times. The length of time will depend on how long your baby will drink for, but will usually be for about 20-30 minutes.

\section{HAS THE STUDY RECEIVED ETHICAL APPROVAL?}

This research study's proposal was submitted to the Faculty of Health Sciences Research Ethics Committee, University of Pretoria as well as the Faculty of Humanities Research Ethics Committee and written approval has been granted by both committees. The study has been structured in accordance with the Declaration of Helsinki (last update: October 2000), which deals with the recommendations guiding doctors in biomedical research involving human subjects. A copy of the Declaration may be obtained from the investigator should you wish to review it.

\section{WHAT ARE YOUR RIGHTS IF YOU TAKE PART?}

You only have to take part in this study if you want to. You can decide not to participate without having to give a reason. You can also decide to stop taking part at any time without giving a reason. If you withdraw from participating, you and your baby will still have access to other medical care. I can also withdraw you and your baby from the study at any time, if I feel that it is not right for you and your baby to continue in the study. Your withdrawal will not affect your baby's access to other medical care.

\section{WILL ANY OF THESE PROCEDURES BE PAINFUL OR UNCOMFORTABLE?}

None of the procedures will be painful or uncomfortable for you or your baby. I will observe a normal breastfeeding session, without interfering while you are feeding. I will touch the outside of your baby's mouth, but this is not uncomfortable or painful for your baby.

\section{WHAT ARE THE RISKS INVOLVED IN THE PROCEDURES?}

- There will be no harm to you or your baby if you decide to take part in this study.

- I will first get permission from your baby's doctor to allow your baby to breastfeed if your baby is not normally breastfed.

- You will be given information about how your baby is breastfeeding after we have finished observing the session.

- If I see that your baby is struggling to breastfeed well, I will refer you to the proper professionals in the hospital.

\section{FINANCIAL ARRANGEMENTS}

You will not be asked to pay to take part in the study. You will also not be paid if you agree to take part in the study. 


\section{CONFIDENTIALITY}

All information obtained during the course of this study is strictly confidential. Data that may be reported in scientific journals will not include any information which identifies your baby as a participant in this study. In connection with this study, it might be important for local regulatory health authorities and the Faculty of Health Sciences Research Ethics Committee, University of Pretoria, as well as your personal doctor, to be able to review your baby's medical records pertaining to this study. This information will be kept for a minimum of 15 years at the Department of Speech-Language Therapy and Audiology, as per University of Pretoria guidelines.

\section{INFORMED CONSENT FOR PARENTS / CAREGIVERS (on behalf of minors under 18 years old)}

I hereby confirm that I have been informed by the investigator, Melissa Pike, about what will take place during the study. I have also received, read and understood the above written information (Patient Information Leaflet and Informed Consent) regarding the study. I am aware that the results of the study, including my child's personal details regarding date of birth, initials and diagnosis will be kept confidential.

I may, at any stage, without any negative consequences, withdraw my consent for participation in the study. I have had sufficient opportunity to ask questions and (of my own free will) declare myself and my baby prepared to participate in the study.

Parent/Guardian(s) Name

(Please print)

Parent/Guardian(s) Signature

Date

Investigator's Name

(Please print)

Investigator's Signature

Date

Witness's Name

(Please print)

Witness's Signature

Date

Interpreter's Name

(Please print)

Interpreter's Signature

Date

\section{VERBAL PATIENT INFORMED CONSENT (applicable when patients cannot read or write)}

I, the undersigned, Melissa Pike, have read and have explained fully to the parent, named and/or his/her relative, the patient information leaflet, which has indicated the nature and purpose of the study in which I have asked the parent's child to participate. The explanation I have given has mentioned both the possible risks and benefits of the study. The parent indicated that he/she understands that his/her child will be free to withdraw from the study at any time for any reason.

I hereby certify that the parent has agreed to participate in this study.

Parent's Name (Please print) 
Investigator's Name

(Please print)

Investigator's Signature

Date

Witness's Name

(Please print)

Witness's Signature

Date

Interpreter's Name

(Please print)

Interpreter's Signature

Date

Private Bag X20, Hatfield, 0028

University of Pretoria

\section{PRETORIA}

Republic of South Africa 
Appendix F:

Northern Sotho parent information and informed consent 


\section{TSIBISO YA MOTSWADI LE BORIFI BA GO DUZELA}

Go anyisa le seya le nako ya pelego ka mo legopheng la thokomele ka mo kangaroo.

MOTSAMAISI WA WA LEFAPHA KE: Melissa Pike

SEKOLO: University Ya Pretoria

MOTŠEGARE KAPA NAKO YA GO IKOPANYA LEYENA:

No ya motšegare ke 0734315422

No ya bosigo ke 0734315422

LETSOTSI LE MATHOMO A GO KOPANA:

\begin{tabular}{|c|c|c|c|}
\hline & & & \\
\hline Letsotsi & Kgwedi & Ngwago & Nako \\
\hline
\end{tabular}

\section{Molwetsi ya rategang}

\section{KETSISO}

Wena le ngwana le laletswa gotla motlhokomelong lengwalo le le batla go tsibisa gore a abatla go tseya karolo. Pele ga o ka tsenela mokhatlo o. Ke tswanele ya gore o thaloganye. Ge gona le mo o sa thaloganyeng teng. Ka yona nako eo o butsise. $\mathrm{O}$ seke wa dumella etsa gore ngwana wa gago a be mo lefapheng, $\mathrm{O}$ sa kgotsofala.

\section{LEBAKA THUPELLO E?}

Thuto e ke go itse lebaka la bana ba babeleweng ke beke 34 go fithla ka 36 le baka la gore ba anyiswe. Ke tumello ya motswadi ke tshoanetse go etsa tse latellang.

- Lebella bukana ya ngoana ya sepetlele, gore kgolo ea ngwana tsamaile bjang.

- Tse botsisang ka boimana le bophelo gago.

- O tshwanetse gp tshwara molomo wa ngwana pelaomo anyisa.

- Lebella tsamaiso le thuto ya go anyisa, gore o tle abone gore lesea le anya bjang, le go metsa.

- Go ngwala ka ngwana, gore o anya bjang gentse a anye.

- Go bana ke omong wa bathlokomedi ge nna ke lebelletse.

Ge ona lemaikemisetso a thlokomelo, ga se gore ngwana o na le mathata. Ge ngwana a sa anye, ka tswanelo, re tla tswanela ke go ikopanya le Ngaka. Ge nna ke le lebelletse ke tsamaile thupelo ya go thlomela gore leseya le any aka tswanelo. Nka se gapeletse lesea, go ira se a sa sebatleng ke thlapa matsogo, pele le morago ga go bonana le ngwana. O ka se aroganywe le ngwana ka nako e. 


\section{THUTO E TSEYA NAKO E KANAKANG?}

Ge wena le ngwana o dumela go tsaya karolo. Ge o dumela o tla be o le w abo 80 mokarolong. Ge o dumetse go tseya karolo, ke bona ngwana wag ago gangwe fella e o santse o le kamo kokelong. G eke go bona, go tla tsa ya nako e kana 45 minutes:

- Ke tla labella bukana ya gago, ka botsisa olipotso go tla tseya nako e kana ka 10-15 metsotso.

- Ke tla batla, go ema ke lebelle ka mokgwa o, o anyisang ngwana ka ona. Na e tla tsamaiswa, ka mokgwa o ngwana a anyang ke teng, go tsega metsostsi e 20-30 minutes.

\section{THUTO E KEREILE TUMELLO E TSHWANETSENG?}

Thupelo e dumelletswa ke lefapha la thlokomelo ya bophelo, ka University ya Pretoria, le komiti ya bophelo. Thuto e ebopilwe ka tumello ya Helsinki pheletso ya teng ke October 2000. E thlokometse maiteko a dingaka. Tlalelletso ya tsibiso e o ka fiwa ge o batla.

\section{TOKELLO TSA GAGO KE TSEFENG?}

O dumelletswe go tsaya karolo ka thato ya gago. O ka-nne wa tlogela ka thato ya gago. O tla nne o kereya di thlokomelo tse ding. Le nna ke dumelletswe, go go lokolla go re o se ke wa be teng, me sethlopeng. Mme ditshwabe le o tla nne o di fumana.

\section{A GONA LE BOTHLOKO KAPA GO SE THABE KA SESENG?}

A gona le bothloko for wena kappa ngwana, ketlo lebelela gago nyantsa ngwana. Ke tlo tswara molomo wa ngwana gao. E kase gobatse ngwana.

\section{KE ENG DI KOTSI TSE DE LENG MO DILONG TSE RE DIRANG?}

- Ga gona bothloko bope ge o batla go tseya karolo.

- Ke tla tshwanela ke go fiwa tokelo mo ngakeng ya leseya lagago ge leseya le sa anye ka tshwanelo.

- O tla fi kitso gore a ngwana o anya pila kapo ga anya pila.

- Ge ka bana gore go batlega thuso, ke tla go somela ko lefapheng, le tswanetseng, ke mo be okelong.

\section{TUKISO TSA DITSHWANELO}

O ka se patelle go tseya karolo, e bile o ka sa patelwe, go tseya karolo.

\section{SEPHIRI}

Boitukisetso bo bo editsweng mo, ke sephisi sa ngaka. Go gona motho ya tla itseng ka wena le leseya la gago. Mabapi le bophelo le ditshwanelo tsa bothlokwa ba tlhokomelo ya leseya, baeta-pele le ngaka ya leseya, ba tshwanela go-bona bo-phelo le thuto. Taba ya leseya la-gago e bolokwa nako e kana ka mengwagae 15 ka mo University.

\section{TUMELLO YA MOTSWADI, MOTHLOKOMEDI KA MO TLASE GA 18 YEARS}

Ke tlaletsa gore, ke dupelletswe ke Melissa Pike ka thupello e tla tsamaiswang. Ke fumane, ebile ke badile, ke thlaloganya, tse ngwetsweng, mabapi le tse di editswen ke sephiri. Ke ka kgona go tlogela ka nako engwe le e ngwe.

Motswadi kappa moemedi

Motswadi go ngwala 
Letsatsi

Mothlathlodi

Mongwalo wa mothlathlodi

Letsatsi

Paki

Mongwalo wa Paki

Letsatsi

Toloki

Mongwalo wa Tolohi

Letsatsi

\section{TUMELLO YA MOLWETSE}

Melissa Pike, o badile a thalosa ka botlalo go molwetse motswadi e le kopileng motswadi go tseya karolo.

Ke tlalelletsa gore motswadi o dumetse tseya karol.

Moemedi

Mothlathlodi

Mongwalo wa mothlathlodi

Letsatsi

Paki

Mongwalo wa Paki

Letsati

Toloki

Mongwalo wa Toloki

Letsatsi 
Appendix G:

isiZulu parent information and informed consent 


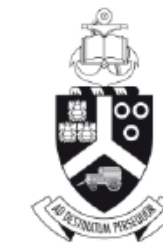

UNIVERSITEIT VAN PRETORIA UNIVERSITY OF PRETORIA YUNIBESITHI YA PRETORIA

Denkleiers • Leading Minds • Dikgopolo tša Dihlalefi Faculty of Humanities

Department of Speech-Language Pathology and Audiology

\section{ISAZISO SO MGULI}

IMFUNDISO: U ku ncelisa usana lokhu asase mncane.

IMFUNDISI: Melissa Pike

ISIKOLO: University of Pretoria

Amanamba: 0734315422

Ebusuku: 0734315422

ISIKWATHI SO KU CALA NO KUKHULUMISANA:

\begin{tabular}{|l|l|l|l|}
\hline & & & \\
\hline Ilanga & Inyanga & Unyaka & Isikhati \\
\hline
\end{tabular}

Umguli o thandekaya

ISAZISO

Wena no mtwana wakho, ni menywa ngo ku thanda, u ku funda. Le mfundo, ku phuma kuwe, ukuthi cay a thanda, noma, a wu thandi. Phambi ko khuti ungene ku le mfundo, u fanele u zwisise kahle. Na u no mbuzo, la u nga zwisisamga, u nga sabi u ku buza. U nga-vumi ngo mfwana wakho, na u nga ijabuleli le mfundo.

\section{YINI E YENZA LE MFUNDO I LUNGE?}

Lena yi-mfundo, yo ku funda ngo mtwana o zalwe nga ma-veki a 34-36. U khuti ngi ku fundise ngi fanele u ku thola imvumelo yokho.

- Beka incwadi yo mtwana ye sibedlela. No kuthi so lokho wa zalwa kuya ka njani ngo mtwana.

- Ba zo ku buza ngo ku zothwala kwakho.

- U ku babba umlomo wo-mtwana, phambi ko kuthi umunyise.

- Beka na be munyisa umtwana, e kucaleni na e munya no ku-gwinya.

- U ku bala no ku buza imbuzo.

- $\quad$ Na o munye umfindisi, o fana name e beka ukuthi, umtwana umunya njani.

Na uvuma uku ngenela le mfundo, a yi-yi no kuthi umtwana u ne-nkinga na kuthi u-mtwana a ka nceli ngi, cela imvumelo, ku dokotela. U khuti ngi beke, na u mtwana e ncela. Ngi fundisilwe nga bantwana na be ncela ngeke si yenze into e umtana a nga kwazi ku yenza. Phambi ko kuthi ngi bambe umtwana wakho, ngo washa izandla. Si ngeke sis use umtwana na si lokho sifunda.

SITHATHA ISIKHATHI ESI-NGAKANANI? 
$\mathrm{Na}$ u vuma ukuthi wena no mtwana ni funde, a bo mam bo u (80) na bantwana babo. Ngi zo ku bona kanya, nan i sase sibedlela. Nge mizuzu e 45.

- $\quad$ Ngi zo funda I ngwadi, ngi buze imbuzo. Ku 20 thatha imizuzu e 10-15.

- Ngi zo bheka, na u lokho u munyisa umtwana. Ngi thatha imzuz e 20-30.

\section{LE MFUNDO I VUNYELWE KWA SE MTHETHWENI?}

Le mfundo ya vunyelwa, emhlanganweni we mpilo, ne sikhundla se University of Pretoria. Im fundo, bunywe ngu Helsinki nge October 2000 I sebenza nge mumo y abo dokotela. U ya fanela u ku thola iphepha lo ku khomba, ukuthi, aphansi kwabo.

\section{LUNGELO LAKHO YINI NA U PHAKATHI KWA LE MFUNDO?}

U nga ngena na u funda. Na ungo funi na khona ku lungile. U nga yeka nge-sikhathi, o ufuna u ku yeko. O kunye kwe sibedlela u zo ku thola. Ngi nga nikhipha, wena no mtwana, na ukuthi ngi bona ni nga faneli.

\section{O KUNYE KWA LEMFUNDO KU BUHLUNGU NA?}

A kuna buhlungu lutho, ku konke o ngi ku yenzayo, ngi zo bamba umlomo wo mtwana na e ncela, a bukho buhlhngu khona lapho.

\section{INGOZI YINI KU LOMFUNDO?}

- Ayikho ingozi kuwe noma umtwana.

- U dokotela wo mtwana u zo ngipha ilungelo na umtwana e nga nceli kakhle. Ukuthi ngi mfundise u ku ncela.

- Si zo ku yazisi na umtwana e ncela kahle, noma a ka nceli kahle.

- Na umtwana e nga nceli kahle, si zo muthumela ke dokotela e fanele.

\section{AMALUNGELO E MALI}

Ngeke u khiphe I mali ku lendawo, ngeke u phiwe i-mali ngo ku ngena ke le-mfundo.

\section{IMFIHLO YA LENDABA}

Zonke izindaba za le mfundo, zi phansi kwa dokotela, wena name nga phansi kwa le nkundla ye University of Pretoria.

\section{IMVUMELO YO MZALI}

Ngi yazisilwe ngo ku-phelela, nga le ndaba ye mfundo ngo: Melissa Pike.

Ngi ka yeka nge-si khathi e ngi-sithandayo. Ngi vumile mina no mtwana, u ku-thata noma ku ngela le mfundo.

Mzali

Mmeli

Ilanga

Mfundisi

Mberlo wo mfundisi

Ilanga 
Mmeli

Umbalo wo mmeli

llanga

Itoliki

Umbalo we toliki

Ilanga

\section{ISAZISO KU MGULI}

Mina, Melissa Pike, ngi fundile nga fundisa u mama incwadi e mfundisa nga konke.

I-gama lika mama

Mfundisi

Mberlo wo mfundisi

llanga

Mmeli

Umbalo wo mmeli

llanga

Itoliki

Umbalo we toliki

llanga

Communication Pathology Building

Dept. of Speech-Language Pathology and Audiology

Corner of Lynnwood Road and Roper Street, Hatfield

Private Bag X20, Hatfield, 0028

University of Pretoria

PRETORIA

Republic of South Africa 
Appendix $\mathrm{H}$ :

Case history capturing checklist 
Name:

Gender:

Nationality:

\section{Ballard Score: \\ Date of birth: \\ Date of assessment: \\ Chronological age:}

\begin{tabular}{|c|c|c|}
\hline Condition & Ideal & Description \\
\hline \multicolumn{3}{|l|}{ Prenatal History } \\
\hline 1. Age of mother & $18-37$ years & \\
\hline 2. Maternal education & Educated & \\
\hline 3. In vitro fertilization & Natural & \\
\hline 4. Repeated spontaneous abortions / still births & None & \\
\hline $\begin{array}{l}\text { 5. Birth order of infant: Higher mortality for } 1^{\text {st }} \text { and } 3^{\text {rd }} \text { born } \\
\text { children }\end{array}$ & & \\
\hline 6. Smoking during pregnancy & No & \\
\hline 7. Alcohol / drug abuse & No & \\
\hline 8. Family history of hearing loss in children & None & \\
\hline 9. Multiple pregnancy & Single & \\
\hline 10. Antenatal care & $\begin{array}{l}-5 \text { visits }<35 w \\
-8 \text { visits }>37 w\end{array}$ & \\
\hline $\begin{array}{l}\text { 11. Previous children: Mental disability, neurological } \\
\text { disability, congenital disorders }\end{array}$ & None & \\
\hline $\begin{array}{l}\text { 12. Viral infections: Cytomegalovirus, Rubella, Syphilis, } \\
\text { Toxoplasmosis, Herpes, TB, colds, flu }\end{array}$ & None & \\
\hline 13. HIVIAIDS or RVD exposed & No & \\
\hline 14. Diabetes & No & \\
\hline 15. Threatened abortion & No & \\
\hline 16. Blood group incompatibility & No & \\
\hline 17. Medication during pregnancy & No & \\
\hline 18. Hospitalization during pregnancy & No & \\
\hline 19. Premature rupture of membranes & No & \\
\hline 20. Placental problems: placenta abruptio / previa & No & \\
\hline 21. Toxemia, Pre-eclampsia / HELLP syndrome & No & \\
\hline 22. Infant born at home / in hospital & In hospital & \\
\hline \multicolumn{3}{|l|}{ 22. Reason for premature birth } \\
\hline \multicolumn{3}{|l|}{ Description of family circumstances } \\
\hline \multicolumn{3}{|l|}{ Employment } \\
\hline \multicolumn{3}{|l|}{ Means of transport } \\
\hline \multicolumn{3}{|l|}{ Involvement of both parents } \\
\hline \multicolumn{3}{|l|}{ Living conditions } \\
\hline Perinatal History & Ideal & Description \\
\hline 23. Birth: Normal / Caesarian section & Normal & \\
\hline 24. Presentation at birth: Vertex / breech & Vertex & \\
\hline 25. Prolapse of cord around neck & None & \\
\hline 26. Instruments used & None & \\
\hline 27. Meconium aspiration & No & \\
\hline 28. Was the baby transported after birth? Reasons & No & \\
\hline 29. *Birth weight & $3200 \mathrm{~g}-3800 \mathrm{~g}$ & \\
\hline 30. Current weight & & \\
\hline
\end{tabular}


31. Weight gain appropriate

32. *Apgar score: $1 \mathrm{~min} \& 5 \mathrm{~min}$

33. *Small for gestational age / Intrauterine growth retardation

34. Oxygen received and duration

35. Ventilation: Type and duration

36. Respiratory distress syndrome: Grade I, II, III, IV

37 . Bronchopulmonary dysplasia

38. Bradycardia and apnoeic attacks

39. Transient tachypnea of the newborn/tachypnea

40. Retinopathy of prematurity

41. Patent ductus arteriosus / Persistent fetal circulation

42. Other heart defects

43. Intra-ventricular haemorrhage: Grade I, II, III, IV

44. Neonatal convulsions

45. Hydrocephalus

46. Neonatal encephalopathy

47. Necrotizing enterocolitis/other gastrointestinal factors

48. Meningitis

49. Septicemia

50. Other infections

51. *Amino glycoside therapy (ototoxic) and duration

52. *Hyperbilirubinaemia

53. Phototherapy received and duration

54. Blood transfusion / received plasma

55. Infant on medications

56. Exclusive breastfeeding

57. Number of days before breast fed

58. On full oral feeds and duration

59. Tube feeding and duration

60 . Cup feeding and duration

61. Amount expressed and given

62. Supplements given

63. Number of days on warm table and in incubator

64. Received developmental appropriate care

65. Number of days in NICU

66. Number of days in KMC

67. Intermittent or continuous KMC

Additional risk factors

68. Cranio-facial abnormalities

69. Other congenital disorders: Describe

70. Hypoxic Ischaemic Encephalopathy/ HIE

71. Hypoglycaemia

72. Currently on oxygen

73. Hypernatraemia

74. Dehydration

75. Anaemia

76. Lactation difficulty

\begin{tabular}{|l|l|}
\hline Yes & \\
\hline $7-10$ & \\
\hline $\begin{array}{l}\text { Gestation age } \\
\text { birth weight }\end{array}$ & \\
\hline$<10$ days & \\
\hline$<10$ days & \\
\hline No & \\
\hline No & \\
\hline No & \\
\hline No & \\
\hline No & \\
\hline No & \\
\hline No & \\
\hline No & \\
\hline No & \\
\hline No & \\
\hline No & \\
\hline No & \\
\hline No & \\
\hline No & \\
\hline No & \\
\hline No & \\
\hline No & \\
\hline No & \\
\hline No & \\
\hline No & \\
\hline No & \\
\hline No & \\
\hline No & \\
\hline None & \\
\hline No & \\
\hline No & \\
\hline None & \\
\hline None & \\
\hline None & \\
\hline None & \\
\hline From birth & \\
\hline Nontinuous & \\
\hline
\end{tabular}


*21 Duration of pregnancy / Duur van swangerskap (WHO, 2012)

$>42$ weeks

38 - 41 weeks

32 - 37 weeks

28-32 weeks
Post mature / Postmatuur

Full term / Voltermyn

Moderate to late preterm / Matige tot laat prematuriteit

Extremely preterm / Ekstreme prematuriteit

*29 Birth weight / Geboortegewig (Southgate \& Pittard, 2001)

$3400 \mathrm{~g} \mathrm{(3} \mathrm{200g} \mathrm{-} 3800 \mathrm{~g}) \quad$ Average birth weight / Gemiddelde geboorte gewig

$1500 \mathrm{~g}-2500 \mathrm{~g}$

$<1500 \mathrm{~g}$

$<1000 \mathrm{~g}$

Low birth weight / Lae geboortegewig

Very low birth weight / Baie lae geboortegewig

Extremely low birth weight / Ekstreme lgg.

*30 Apgar score as indicator of neonatal asphyxia

Apgartelling as aanduiding van neonatale asfiksie

(Rossetti, 2001)

$1 / 5$ Minute Apgar score

Serious asphyxia

Moderate asphyxia

Normal
0-3 Ernstige asfiksie

4-6 Matige asfiksie

7-10 Normaal

\section{*31 Small-for-gestational age / Klein vir gestasie ouderdom}

Consult Table 1.10 for average fetal weight and size for gestational age in Rossetti, 2001:17.

\section{*46 Amino glycosides / Aminoglukosides (ototoxic medication)} (MIMS Medical Specialities, 1991)

Ototoxic drugs / Ototoksiese medikasie

Amicacin/Amiken, Fermentomycin, Garamycin, Gentomycin, Canamycin, Netromycin, Streptomycin, Tobromycin, Vancomycin.

*46 Hyperbilirubinaemia / Hiperbilirubinemie (JCIH, 2007)

Bilirubin levels of more than 200 micro $\mathrm{ml}$ and a blood transfusion are high risk factors for sensorineural hearing loss and auditory neuropathy spectrum disorder

Bilirubinvlakke van meer as 200 micro $\mathrm{ml}$ en 'n bloedtransfusie is hoërisikofaktore vir sensories-neurale gehoorverlies en ouditiew neuropatie spektrumafwyking 
Appendix I:

Preterm Infant Breastfeeding Behavior Scale 
Appendix 3. Preterm Infant Breastfeeding Behavior Scale (PIBBS

UPPSALA UNIVERSITY

BREASTFEEDING DIARY

Pediatric Department

Kerstin Hedberg Nyqvist, RN

Infant No

Mark the description of your baby's behavior with a cross (only one choice per item) that agreed most with his/her behavior during each breastfeeding session. Choose your baby's best behavior if he/she showed different behaviors under the same item it is sufficient if he/she did so only once. Regarding general behaviors you may mark more than one choice

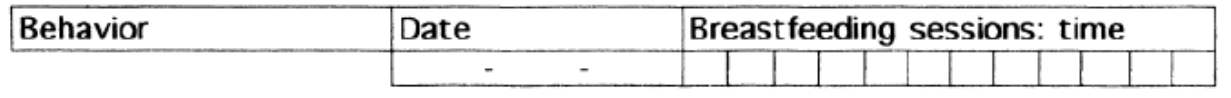

Rooting

Showed no rooting

Showed some rooting

Showed obvious rooting

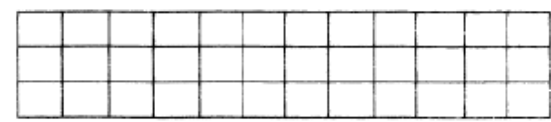

How much of the breast was inside the baby's mouth

Nothing, only touched the nipple

Part of the nipple

The whole nipple, no part of the areola

The nipple and some of the areola

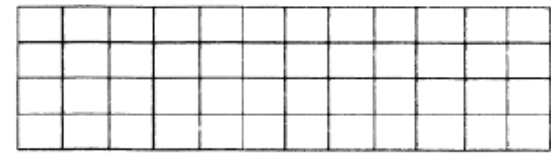

Latched on and stayed fixed to the nipple

Did not latch on at all

Latched on, stayed fixed for less than a minute

Mark with a cross on the

line to show how many

minutes he/she stayed

fixed to the nipple
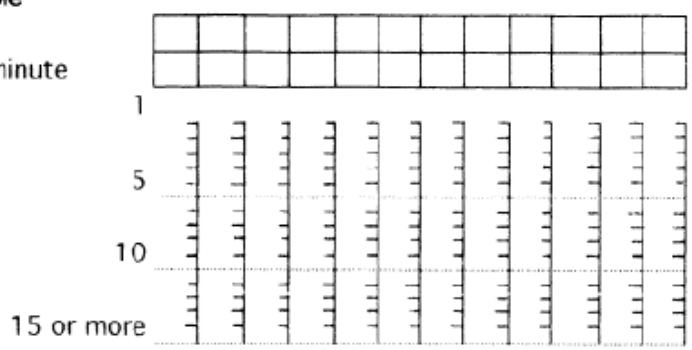

\section{Sucking}

No sucking or licking

Licking and tasting, but no sucking

Single sucks, occasional short sucking bursts Repeated short sucking bursts (2-9 sucks),

maybe occasional long bursts

Repeated long sucking bursts ( 10 sucks or more)

The longest sucking burst

Count how many times he/she

sucked before making a pause:

mark with a cross on the line

for the longest sucking burst

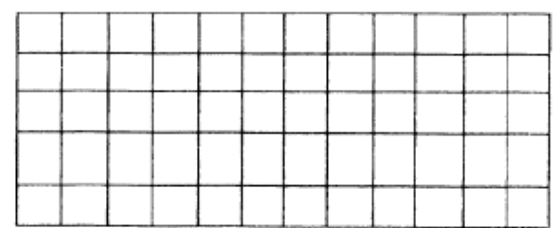

10

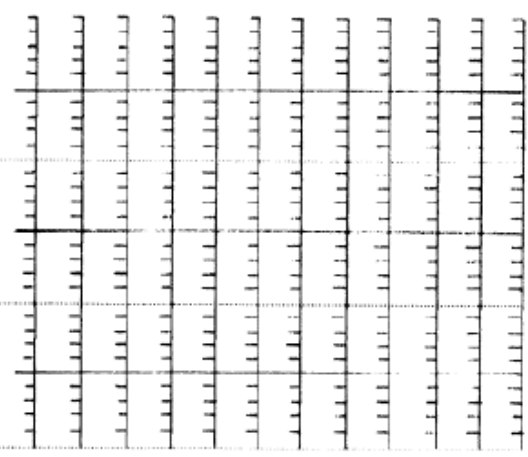

30 or more 
Behavior

\section{Swallowing}

Swallowing was not noticed

Occasional swallowing was noticed

Repeated swallowing was noticed

What did your baby look like: general behavior

Mark with a cross each behavior he/she showed, even

if it only lasted for a very short time

1. Closed eyes, no body movements

2. Drowsy: eyes open but heavy-lidded, eyelids fluttered, a minimum of movements

3. Open eyes: dull or glazed look, (seemed to look through rather than at something), a minimum of movements

4. Eyes wide open: looked tense or afraid, a minimum of movements

5. Eyes wide open: achieved eye contact, looked calm or satisfied, a minimum of movements

6. Closed eyes, active movements in arms, legs, body

7. Open eyes, active movements in arms, legs, body

8. Cried, fussed audibly

\section{Breastfeeding session: time}

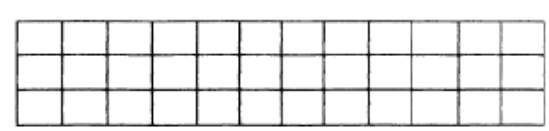

\section{Letdown reflex}

Was not noticed

Was noticed

Time you held your baby (minutes)

Please note: If your baby made a pause of 30 minutes or

more, this was a new breastfeeding session:

Fill in time and a new column

\section{Breast problems/Nipple shield/Oxytocin spray}

No problems

Swollen

Nipples flat or inverted

Fissures or pain

Used nipple shield

Used Oxytocin spray
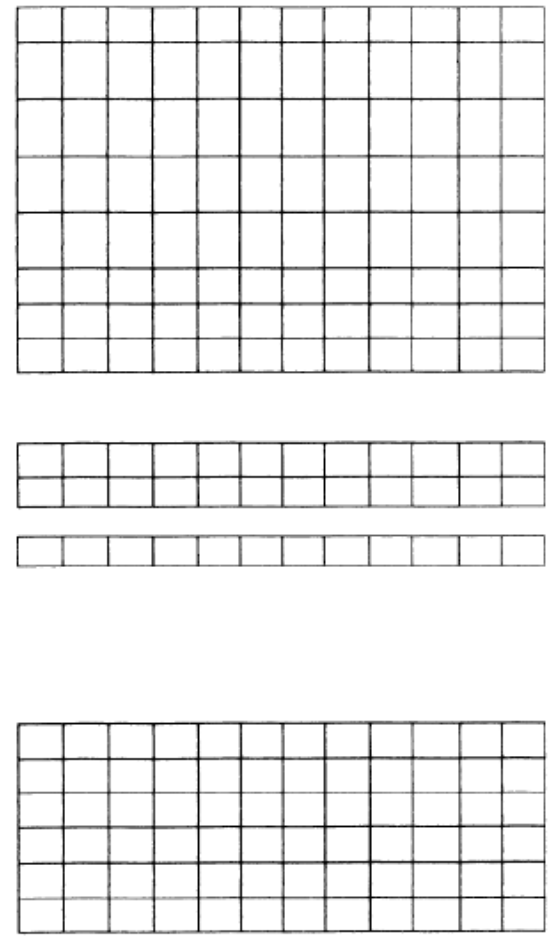

\section{Influence of the environment}

Activity nearby/the presence of others: very disturbing Activity nearby/the presence of others: rather disturbing Enough quiet and privacy

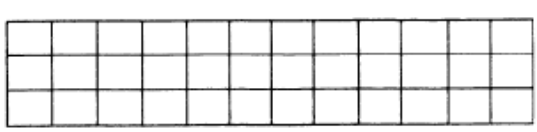

\section{Comments}

Write down anything that may add to the description of your baby's behavior, and anything you consider important for the breastfeeding session, such as your baby's recent experiences, how you felt, if you were comfortable etc. indicate the time of the breastfeeding session concerned. 
Appendix J:

Proof of article submission to Breastfeeding Medicine 


\section{Breastfeeding Medicine}

Breastfeeding Medicine: http://mc.manuscriptcentral.com/breastfeedingmed

\section{Breastfeeding Characteristics of Late-Preterm Infants in a} Kangaroo Mother Care Unit

\begin{tabular}{|c|c|}
\hline Journal: & Breastfeeding Medicine \\
\hline Manuscript ID & BFM-2017-0055 \\
\hline Manuscript Type: & Original Papers \\
\hline Date Submitted by the Author: & 24-Apr-2017 \\
\hline Complete List of Authors: & $\begin{array}{l}\text { Pike, Melissa; University of Pretoria, Speech-Language Pathology and } \\
\text { Audiology } \\
\text { Kritzinqer, Alta; University of Pretoria, Speech-Lanquage Pathology and } \\
\text { Audiology } \\
\text { Krüger, Esedra; University of Pretoria, Speech-Language Pathology and } \\
\text { Audiology }\end{array}$ \\
\hline Keyword: & Prematurity $<$ Infant diseases \\
\hline $\begin{array}{r}\text { Manuscript Keywords (Search } \\
\text { Terms): }\end{array}$ & breastfeeding characteristics, kangaroo mother care, late-preterm infants \\
\hline
\end{tabular}

SCHOLARONE

Manuscripts 
Appendix K:

Decision letter Breastfeeding Medicine 


\section{Decision Letter (BFM-2017-0055.R1)}

From: arthur.eidelman@gmail.com

To: pikemelissa2@gmail.com, Alta.Kritzinger@up.ac.za

CC:

Subject: Breastfeeding Medicine - Decision on Manuscript ID BFM-2017-0055.R1

Body: 26-Jun-2017

Dear Ms. Pike:

Manuscript ID BFM-2017-0055.R1 entitled "Breastfeeding Characteristics of Late-Preterm Infants in a Kangaroo Mother Care Unit" which you submitted to Breastfeeding Medicine, has been reviewed. The comments of the reviewer are included at the bottom of this letter.

I am happy to inform you that it is provisionally accepted for publication pending your response to the points made by the reviewers. Therefore, I invite you to respond to the comments and revise your manuscript accordingly. Please note that a final formal decision as to publication will be made only after submission of the revised manuscript.

To revise your manuscript, log into https://mc.manuscriptcentral.com/breastfeedingmed and enter your Author Center, where you will find your manuscript title listed under "Manuscripts with Decisions." Under "Actions," click on "Create a Revision." Your manuscript number has been appended to denote a revision.

You will be unable to make your revisions on the originally submitted version of the manuscript. Instead, revise your manuscript using a word processing program and save it on your computer. Please also highlight the changes to your manuscript within the document by using the track changes mode in MS Word or by using bold or colored text.

Once the revised manuscript is prepared, you can upload it and submit it through your Author Center.

When submitting your revised manuscript, you will be able to respond to the comments made by the reviewer(s) in the space provided. You can use this space to document any changes you make to the original manuscript. In order to expedite the processing of the revised manuscript, please be as specific as possible in your response to the reviewer(s).

IMPORTANT: Your original files are available to you when you upload your revised manuscript. Please delete any redundant files before completing the submission.

Because we are trying to facilitate timely publication of manuscripts submitted to Breastfeeding Medicine, your revised manuscript should be uploaded as soon as possible. If it is not possible for you to submit your revision by 26-Jul-2017, we will have to consider your paper as a new submission.

Once again, thank you for submitting your manuscript to Breastfeeding Medicine and I look forward to receiving your revision.

Sincerely,

Arthur I. Eidelman, MD FABM FAAP

arthur.eidelman@gmail.com

Reviewer(s)' Comments to Author:

Reviewer: 1

Comments to the Author

Thank you for the edits to your manuscripts. I have a few more suggestions.

1) The last two sentences of the middle paragraph on page four beginning at the end of 
line 36 might be better stated. "KMC may protect breastfeeding in this population, as lower rates of breastfeeding exclusivity and duration are found in LPIs as compared to term infants, and thus allow them to better achieve the global standard of exclusive breastfeeding for the first six months of life."

2) Line 42 page five. Might read better if the two sentences were combined. "Infants should typically have established oral feeding on admission into the unit, where the Baby Friendly Hospital Initiative (BFHI) is implemented."

3 ) Line 9 page 6 . Does the second sentence of the first paragraph make sense? I am not sure you need it at all??

4) The discussion in the second paragraph of page 11 is very important. I suggest the following edits beginning in the middle of line 37. In stead of beginning As the results..., "Our results suggest that participants, as a group, were not efficient breast-feeders and the shorter time held for breastfeeding may be an indication of poor endurance due to the high rate of respiratory difficulties $(15 \%$ required oxygen at the time of evaluation and almost $50 \%$ had RDS)." I would begin the next sentence as you have with, Length of time held for breastfeeding....line 54 .

5) Table 2 is very important. Did you or could you analyze the data by adjusted gestational age of the participants rather than chronological age? That is a nine day old born at 34 weeks would be adjusted to approximately 35.5 weeks and a 9 day old born at 36 weeks would be adjusted to 37.5 weeks. I realize this may be difficult without precise obstetrical dating. Lumping infants born over the three week period as one age group in doing this analysis may well miss maturational differences.

6) Could you or did you analyze the data comparing those with and without respiratory distress? It would be interesting to see this analysis.

This is good information.

Date Sent: 26-Jun-2017 